\title{
Peritoneal Dialysis Guidelines 2019 Part 2: Main Text (Position paper of the Japanese Society for Dialysis Therapy)
}

Munekazu Ryuzaki ${ }^{*}$, Yasuhiko Ito ${ }^{2}$, Hidetomo Nakamoto ${ }^{3}, Y_{\text {Yichi Ishikawa }}^{4}$, Noritomo Itami ${ }^{5}$, Minoru Ito ${ }^{6}$, Atsushi Ueda ${ }^{7}$, Yoshie Kanazawa ${ }^{8}$, Hideki Kawanishi ${ }^{9}$, Yoshihiko Kanno ${ }^{10}$, Hitoshi Sugiyama ${ }^{11}$, Kazuhiko Tsuruya ${ }^{12}$, Hiroyuki Terawaki ${ }^{13}$, Tadashi Tomo ${ }^{14}$, Mizuya Fukasawa ${ }^{15}$, Akihiro C. Yamashita ${ }^{16}$, Hideki Yokoi ${ }^{17}$, Masaaki Nakayama ${ }^{18}$, Hidemichi Yuasa ${ }^{19}$, Yasushi Tsujimoto ${ }^{20}$, Hiraku Tsujimoto ${ }^{21}$, Yosuke Saka ${ }^{22}$, Yusuke Kuroki ${ }^{23}$, Kaoru Yasuda ${ }^{24}$, Takayuki Fujii ${ }^{25}$, Atsuhiro Kanno ${ }^{26}$, Emi Fujikura ${ }^{27}$, Kimio Watanabe ${ }^{18}$, Yoko Obata ${ }^{28}$, Miho Murashima ${ }^{29}$, Naohiro Toda ${ }^{30}$, Shuto Yamamoto ${ }^{31}$, Yoshihiro Tsujimoto ${ }^{32}$, Tsutomu Sakurada ${ }^{33}$, Daisuke Komukai ${ }^{34}$, Kiyotaka Uchiyama ${ }^{35}$, Naoki Washida ${ }^{36}$, Kohkichi Morimoto ${ }^{37}$, Takahiro Kasai ${ }^{36}$, Yukio Maruyama ${ }^{38}$, Chieko Higuchi ${ }^{39}$, Hiroaki $10^{40}$, Keiichi Wakabayashi ${ }^{41}$ and on behalf of the Working Group on Revision of Peritoneal Dialysis Guidelines of the Japanese Society for Dialysis Therapy

\begin{abstract} developed by the GRADE working group.

\footnotetext{
* Correspondence: ryuzaki-m@saichu.jp

This article was translated from Japanese with permission from the JSDT. The original article was published as "2019 JSDT Guidelines for Peritoneal Dialysis" as a book of the Japanese Society for Dialysis Therapy book series 1 published November 18, 2019.

${ }^{1}$ Department of Nephrology, Tokyo Saiseikai Central Hospital, Tokyo, Japan

Full list of author information is available at the end of the article
}

Background: This article is a duplicated publication from the Japanese version of "2019 JSDT Guidelines for Peritoneal Dialysis" with permission from the Japanese Society for Dialysis Therapy (JSDT). This clinical practice guideline (CPG) was developed primarily by the Working Group on Revision of Peritoneal Dialysis (PD) Guidelines of the Japanese Society for Dialysis Therapy. Recently, the definition and creation process for CPGs have become far more rigorous; traditional methods and formats no longer adhere to current standards. To improve the reliability of international transmission of our findings, CPGs are created in compliance with the methodologies developed by the Grading of Recommendations, Assessment, Development and Evaluation (GRADE) working group. Part 2 of this PD guideline is the first CPG developed by our society that conforms to the GRADE approach.

Methods: Detailed processes were created in accordance with the Cochrane handbook and the GRADE approach

Results: Clinical question (CQ)1: Is the use of renin-angiotensin system inhibitors (RAS inhibitors), such as angiotensin-converting enzyme inhibitors (ACEI) and angiotensin receptor blockers (ARB), effective in PD patients? Recommendation: We suggest the usage of RAS inhibitors (ACEl and ARB) in PD patients (GRADE 2C). CQ2: Icodextrin or glucose solution: which is more useful as a dialysate among patients with PD?

C The Author(s). 2021 Open Access This article is licensed under a Creative Commons Attribution 4.0 International License, which permits use, sharing, adaptation, distribution and reproduction in any medium or format, as long as you give appropriate credit to the original author(s) and the source, provide a link to the Creative Commons licence, and indicate if changes were made. The images or other third party material in this article are included in the article's Creative Commons licence, unless indicated otherwise in a credit line to the material. If material is not included in the article's Creative Commons licence and your intended use is not permitted by statutory regulation or exceeds the permitted use, you will need to obtain permission directly from the copyright holder. To view a copy of this licence, visit http://creativecommons.org/licenses/by/4.0/ The Creative Commons Public Domain Dedication waiver (http://creativecommons.org/publicdomain/zero/1.0/) applies to the data made available in this article, unless otherwise stated in a credit line to the data. 


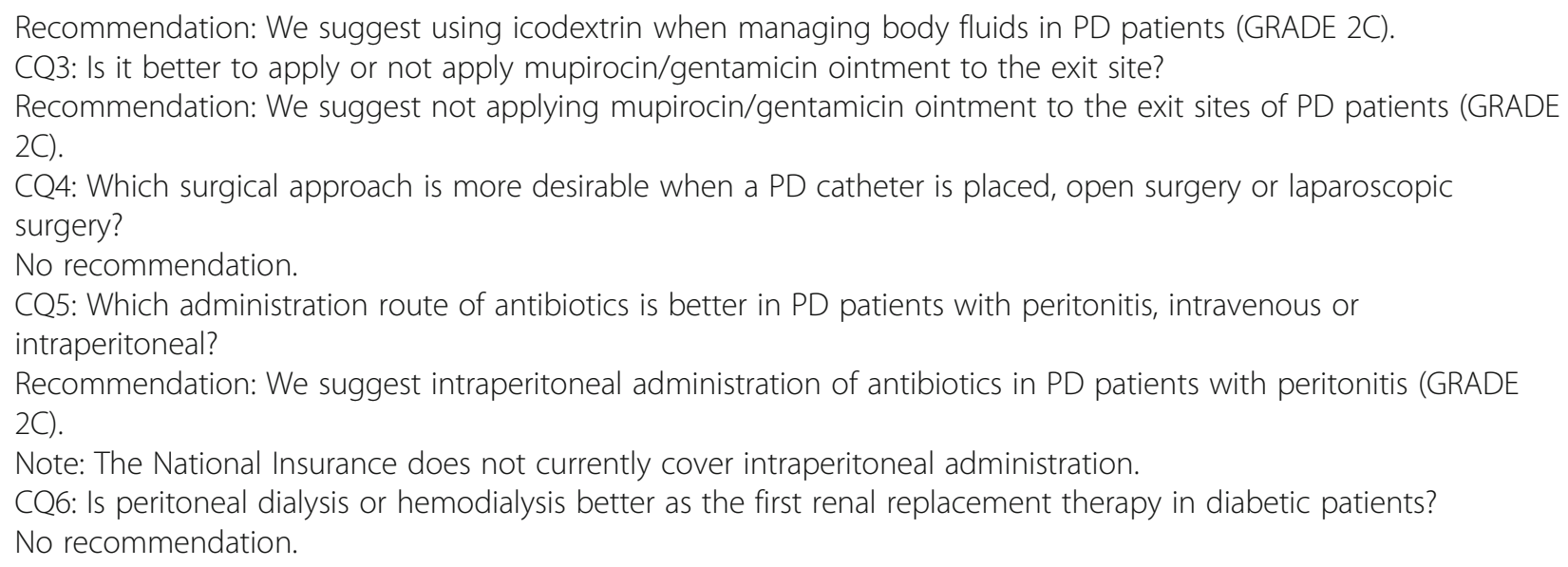

Conclusions: In the future, we suggest that society members construct their own evidence to answer CQs not brought up in this guideline, and thereby show the achievements of Japan worldwide.

\section{Background}

This clinical practice guideline (CPG) was developed primarily by the Working Group on Revision of Peritoneal Dialysis Guidelines of the Japanese Society for Dialysis Therapy (JSDT). To date, the society has developed CPGs and their revised versions either alone or in concert with other organizations, which have been translated into English and disseminated worldwide. These guidelines have been formatted in the form of a textbook, and their content has been useful to dialysis therapists who comprise the members of our society. In part 1 , we have included textbook-like information in line with the first edition of the peritoneal dialysis (PD) guidelines in 2009. However, the definition and creation process for CPGs have become far more rigorous, and traditional methods and formats no longer adhere to the recent current standards. Since 2012, the Guidelines and Procedures Creative Working Group (formerly the Guidelines Committee) has considered the methods for the creation of guidelines and has formulated a policy document discussing the methods to be used in the creation of guidelines [1]. Furthermore, to improve the reliability of international transmission of our findings, this policy document dictates that CPGs are to be created in compliance with the methodologies developed by the GRADE working group. Part 2 of this PD guideline is the first CPG developed by our society that conforms to the Grading of Recommendations, Assessment, Development and Evaluation (GRADE) approach.

In the field of PD where evidence is often scarce, the development of a CPG in accordance with the GRADE approach is difficult. Furthermore, the little evidence that is rarely transmitted from within Japan raises doubts as to whether the guidelines developed on such a foundation can truly be said to be Japanese. Thus, there are several CQs that had to be removed due to an overwhelming lack of evidence. At present, we are proud that this CPG is based on the evidence we were able to gather, and was formulated through appropriate methodical analysis. While our recommendations are academically sound, some of the involved procedures were not listed in the insurance coverage. Hence, we would like to emphasize that these recommendations are merely academic advices. Furthermore, due to both lack of evidence and certainty, none of our recommendations were under the "strong" category. In other words, the society would like to make it very clear that the procedures not recommended are by no means unadvised or rejected. No two patients are alike, and yet, the recommendation categories were determined using current statistical methods that necessarily paint all patients with the same broad brush. Thus, as a clinical course, clinicians using these guidelines must reject our weak suggestions for methodologies not recommended after considering the unique pathologies of their individual patients. As seen in Section 3, clinicians regularly opt for non-recommended methodologies in the real clinical setting even when a strongly recommended course of action exists. When it comes to weakly suggested courses of action, a great deal of variance exists between cases with relatively similar methodologies. In other words, we would like to emphasize that the "recommendations" listed here are not mandates to be performed in all scenarios.

Additionally, because we received input that information highly desired by society members should be incorporated in the form of CQs, we collected challenge CQs and outside opinions to a certain extent. In particular, we received the following CQs: (i) whether hemodialysis (HD) or PD is better for patients with chronic renal 
failure who require dialysis, (ii) what type of PD treatment is best for these patients who select PD, (iii) what sorts of harm or burden exists for each of these treatment options, (iv) which has the best survival rate, and (v) whether or not the length of hospitalization or hospital visits should be reduced. Since the individual circumstances of patients can vary significantly, PD has already been established as a standard treatment worldwide, and studies comparing HD and PD monotherapy do not exist. We have judged these questions to be difficult to answer. We speculate that these sort of comparative trials are unlikely to be properly conducted in the future. In comparison to HD, in which a comparatively consistent level of treatment is maintained, for PD (as we discuss in Peritoneal Dialysis Outcomes and Practice Patterns Study (PDOPPS)), the incidence of peritonitis, treatment continuation rates, and dropout rates vary significantly from facility to facility. There is also the issue of which level of PD to be considered in comparison with HD. To improve the treatment level and achieve uniformity, we believe that discussion is necessary after the guidelines has been disseminated. After considering the matter among our working group, we have decided to limit to only one challenge CQ (CQ6) due to reasons including an overwhelming lack of evidence. Although we considered a total of $7 \mathrm{CQs}$, there was not enough evidence to answer CQ7. Hence, we included only six of them. In the future, we suggest that society members construct their own evidence and answer CQs not brought up in this iteration of the guidelines. Thereby, this may showcase the achievements of Japan worldwide.

\section{Summary of recommendations}

CQ1: Is the use of renin-angiotensin system inhibitors (RAS inhibitors), such as angiotensin-converting enzyme inhibitors (ACEI) and angiotensin receptor blockers (ARB), effective in peritoneal dialysis patients? The conceptual diagram of clinical questions is depicted in Fig. 1.

Recommendation: We suggest the usage of RAS inhibitors (ACEI and ARB) in PD patients (GRADE 2C).
CQ2: Icodextrin or glucose solution: which is more useful as a dialysate among patients with PD? Recommendation: We suggest using icodextrin when managing body fluids in PD patients (GRADE 2C). CQ3: Is it better to apply or not apply mupirocin/ gentamicin ointment to the exit site?

Recommendation: We suggest not applying mupirocin/ gentamicin ointment to the exit sites of PD patients (GRADE 2C).

CQ4: Which surgical approach is more desirable when a PD catheter is placed, open surgery or laparoscopic surgery?

No recommendation.

CQ5: Which administration route of antibiotics is better in peritoneal dialysis patients with peritonitis, intravenous or intraperitoneal?

Recommendation: We suggest intraperitoneal administration of antibiotics in PD patients with peritonitis (GRADE 2C).

Note: The National Insurance does not currently cover intraperitoneal administration.

CQ6: Is PD or HD better as the first renal replacement therapy in diabetic patients?

No recommendation.

\section{Methods}

\section{About our guideline creation approach}

The definition of the CPG used herein and the overall construction of this document were in accordance with the CPG creation policy developed by the Japanese Society for Dialysis Therapy [1-3]. Detailed processes were created in accordance with the Cochrane handbook and the GRADE approach developed by the Grading of Recommendations, Assessment, Development and Evaluation (GRADE) working group [2, 4, 5] (Tables 1 and 2).

For Japanese terminology, we referred to the "Minds CPG Creation Procedures" created by the Minds (Japan Council for Quality Health Care, EBM Medical Information Division) [6, 7]. However, our creation methodology was developed in line with the GRADE approach.

\section{Audience of this PD CPG}

The target audience for this CPG is doctors who treat patients requiring PD therapy.

Table 1 Grades and definitions of evidence quality in CPGs [1]

\begin{tabular}{ll}
\hline $\begin{array}{l}\text { Evidence } \\
\text { certainty }\end{array}$ & Definition \\
\hline A: High & We are very sure that the true effect is close to the estimated effect value. \\
B: Moderate & $\begin{array}{l}\text { We have a moderate level of confidence in the estimated effect value. In other words, we cannot rule out the possibility that } \\
\text { they may be very different. }\end{array}$ \\
C: Low & $\begin{array}{l}\text { Our confidence in the estimated effect value is limited. The true and estimated effects may be very different. } \\
\text { D: Very low }\end{array}$ \\
\end{tabular}


Table 2 Meanings of recommendation strengths for the guideline user [1]

\begin{tabular}{ll}
\hline Recommendation strength & Definition \\
$\begin{array}{l}\text { 1: Strong recommendation } \\
\text { (recommendation) }\end{array}$ & $\begin{array}{l}\text { We are strongly confident that the desirable effect of the intervention (the benefit) surpasses (or, in certain } \\
\text { cases, does not surpass) its undesirable effects (adverse effect, burden, cost). From the perspective of the } \\
\text { patient, nearly everyone in the given situation would want to proceed with the recommended course of action, } \\
\text { while only few individuals would not. }\end{array}$ \\
$\begin{array}{l}\text { 2: Weak recommendation } \\
\text { (suggestion) }\end{array}$ & $\begin{array}{l}\text { We are weakly confident that the desirable effect of the intervention (the benefit) surpasses (or, in certain cases, } \\
\text { does not surpass) its undesirable effects (adverse effect, burden, cost). From the perspective of the patient, } \\
\text { many in the given situation would want to proceed with the recommended course of action, but many may } \\
\text { not want to proceed with the intervention. }\end{array}$ \\
\hline
\end{tabular}

\section{Results/recommendations}

CQ1: Is the use of RAS inhibitors, such as ACEI and ARB, effective in peritoneal dialysis patients?

\section{Recommendation}

We suggest the use of RAS inhibitors (ACEI and ARB) in PD patients (GRADE 2C).

\section{About this CQ}

RAS inhibitors, such as ACEI and ARB, have renoprotective effects and reduce proteinuria. These are also drugs often used to treat chronic kidney disease. Previous studies have shown that preserving residual renal function in $\mathrm{PD}$ patients is beneficial to their prognosis. Herein, we examined whether or not the administration of RAS inhibitors to PD patients was effective.

While ACEI and ARB act via different mechanisms, we have grouped them together as RAS inhibitors for the purpose of this systematic review (SR) and have collectively considered them in SR1.1. The market share of ARB in Japan far outweighs that of ACEI. Hence, we determined that considering each separately was not reflective of the reality. Conversely, we have considered the matter in SR1.2 anticipating that we would receive questions as to whether ACEI or ARB are more effective for PD patients (Tables 3 and 4).

\section{Basis of our judgment}

We investigated SR1.1 and SR1.2; however, we were unable to determine which of ACEI and ARB was superior to the other for SR1.2. Consequently, we collectively treated ACEI and ARB as RAS inhibitors and have used SR1.1, which considers their effectiveness as the basis for our recommendation.

The certainty of evidence was assessed to be low critical importance, and the certainty of the evidence in general was also judged to be low.

Many of the cases involved RAS inhibitors being administered to patients prior to the introduction of PD. If one were to say that this pattern of administration is beneficial, nearly no cases would involve patient rejection of the drug. Additionally, previous studies have already clarified the relationship between residual renal function and the prognosis of PD patients. For this SR, we used urine volume as an index of residual renal function (a few studies that used eGFR as an index were also identified). Maintenance of urine volume is an appropriate index through which the patient can judge whether

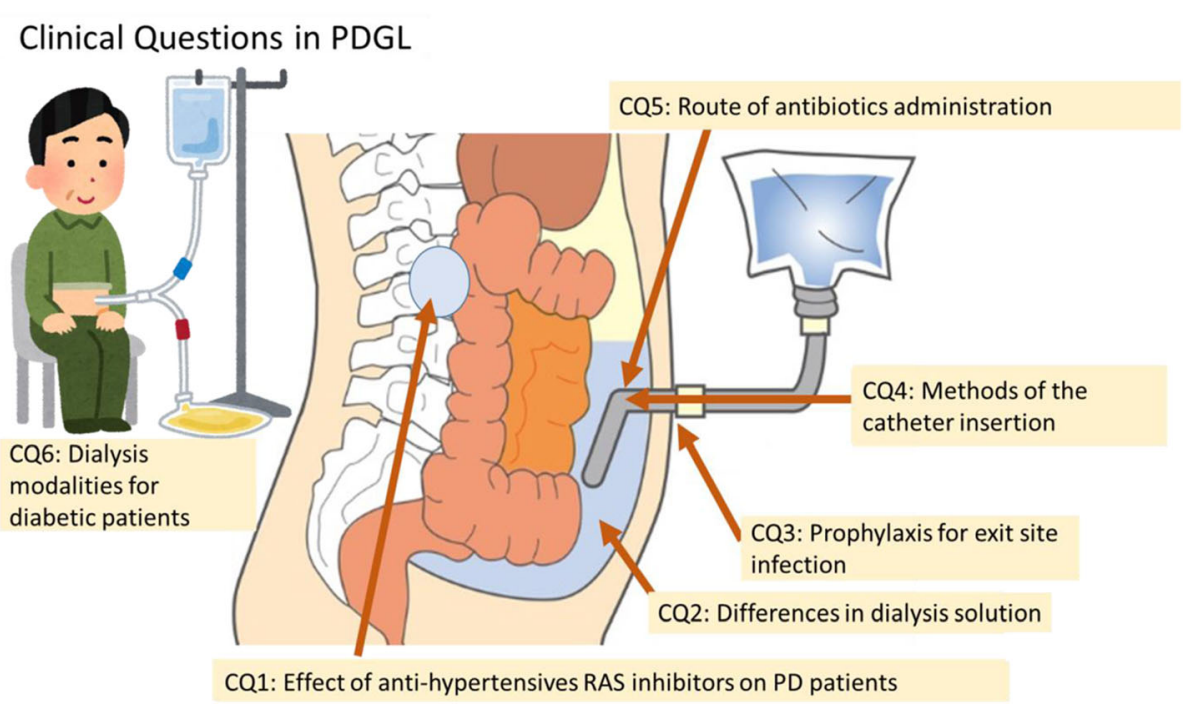

Fig. 1 Conceptual diagram of clinical questions (CQs) 
Table 3 Evidence profile: SR1.1. Comparison of ACEI and ARB with other drugs

\begin{tabular}{|c|c|c|c|c|c|c|c|c|c|c|c|c|}
\hline \multicolumn{7}{|c|}{ Certainty assessment } & \multicolumn{2}{|c|}{$\begin{array}{l}\text { Number of } \\
\text { patients }\end{array}$} & \multicolumn{2}{|l|}{ Effect } & \multirow[t]{2}{*}{ Certainty } & \multirow[t]{2}{*}{ Importance } \\
\hline $\begin{array}{l}\text { No. of } \\
\text { studies }\end{array}$ & $\begin{array}{l}\text { Study } \\
\text { design }\end{array}$ & $\begin{array}{l}\text { Bias } \\
\text { risk }\end{array}$ & Inconsistency & Indirectness & Inaccuracy & Other & $\begin{array}{l}\text { ARB, } \\
\text { ACEI }\end{array}$ & $\begin{array}{l}\text { Other } \\
\text { drugs }\end{array}$ & $\begin{array}{l}\text { Relative } \\
{[95 \% \mathrm{Cl}]}\end{array}$ & $\begin{array}{l}\text { Absolute } \\
(95 \% \mathrm{Cl})\end{array}$ & & \\
\hline \multicolumn{13}{|c|}{ Overall survival rate (number of deaths due to events) } \\
\hline 6 & $\mathrm{RCT}$ & $\begin{array}{l}\text { Serious } \\
\text { a }\end{array}$ & Not serious & Not serious & Serious $^{b}$ & None & $\begin{array}{l}3 / 135 \\
(2.2 \%)\end{array}$ & $\begin{array}{l}2 / 104 \\
(1.9 \%)\end{array}$ & $\begin{array}{l}\text { Cannot } \\
\text { estimate }\end{array}$ & $\begin{array}{l}\text { No change } \\
\text { per } 1000 \\
\text { patients (40 } \\
\text { patients } \\
\text { decreased to } \\
50 \text { patients } \\
\text { increased) }\end{array}$ & $\begin{array}{l}\oplus \oplus \circ O \\
\text { Low }\end{array}$ & Critical \\
\hline \multicolumn{13}{|c|}{ Technical survival (PD continuation period, PD withdrawal) (PD withdrawal) } \\
\hline 6 & $\mathrm{RCT}$ & $\underset{c}{\text { Serious }}$ & Not serious & Not serious & Serious $^{d}$ & None & $\begin{array}{l}3 / 134 \\
(2.2 \%)\end{array}$ & $\begin{array}{l}3 / 104 \\
(2.9 \%)\end{array}$ & $\begin{array}{l}\text { Cannot } \\
\text { estimate }\end{array}$ & $\begin{array}{l}\text { No change } \\
\text { per } 1000 \\
\text { patients (50 } \\
\text { patients } \\
\text { decreased to } \\
40 \text { patients } \\
\text { increased) }\end{array}$ & $\begin{array}{l}\oplus \oplus \circ \circ \\
\text { Low }\end{array}$ & Critical \\
\hline \multicolumn{13}{|c|}{ Technical survival (PD continuation period/PD withdrawal) (peritonitis) } \\
\hline 2 & $\mathrm{RCT}$ & $\begin{array}{l}\text { Not } \\
\text { serious }\end{array}$ & Not serious & Serious ${ }^{\mathrm{e}}$ & Serious $^{f}$ & None & $\begin{array}{l}12 / 48 \\
(25.0 \%)\end{array}$ & $\begin{array}{l}12 / 46 \\
(26.1 \%)\end{array}$ & $\begin{array}{l}\text { RR } 0.98 \\
{[0.49-} \\
1.95]\end{array}$ & $\begin{array}{l}\mathbf{5} \text { patients } \\
\text { decreased } \\
\text { per } 1000 \\
\text { patients }(248 \\
\text { patients } \\
\text { decreased to } \\
133 \text { patients } \\
\text { increased) }\end{array}$ & $\begin{array}{l}\oplus \oplus \circ O \\
\text { Low }\end{array}$ & Important \\
\hline \multicolumn{13}{|c|}{ Urine volume/residual renal function (urine volume) } \\
\hline 6 & RCT & ${ }_{c}^{\text {Serious }}$ & Not serious & Not serious & Serious $^{9}$ & None & 105 & 89 & - & $\begin{array}{l}\text { MD } 142.56 \\
\mathbf{m L} \text { increase } \\
\text { (25.42 mL } \\
\text { increase to } \\
259.69 \mathrm{~mL} \\
\text { increase) }\end{array}$ & $\begin{array}{l}\oplus \oplus \circ O \\
\text { LoW }\end{array}$ & Critical \\
\hline \multicolumn{13}{|c|}{ Urine volume/residual renal function (anuria) } \\
\hline 3 & RCT & $\underset{c}{\text { Serious }}$ & Not serious & Not serious & Serious $^{h}$ & None & $\begin{array}{l}23 / 67 \\
(34.3 \%)\end{array}$ & $\begin{array}{l}29 / 59 \\
(49.2 \%)\end{array}$ & $\begin{array}{l}\text { RR } 0.70 \\
{[0.48-} \\
1.02]\end{array}$ & $\begin{array}{l}147 \text { patients } \\
\text { decreased } \\
\text { per } 1000 \\
\text { patients }(256 \\
\text { patients } \\
\text { decreased to } \\
10 \text { patients } \\
\text { increased) }\end{array}$ & $\begin{array}{l}\oplus \oplus \circ \circ \\
\text { LoW }\end{array}$ & Critical \\
\hline \multicolumn{13}{|c|}{ Urine volume/residual renal function (GFR) } \\
\hline 4 & $\mathrm{RCT}$ & Serious & Not serious & Not serious & Serious $^{j}$ & None & 87 & 76 & - & $\begin{array}{l}\text { MD } \mathbf{0 . 9 7} \\
\text { increase }(0.49 \\
\text { decrease to } \\
1.44 \text { increase) }\end{array}$ & $\begin{array}{l}\oplus \oplus \circ \bigcirc \\
\text { LoW }\end{array}$ & Critical \\
\hline \multicolumn{13}{|c|}{ Dialysis volume (total Kt/N) } \\
\hline 3 & RCT & $\underset{c}{\text { Serious }}$ & Not serious & Serious $^{k}$ & Serious ${ }^{\prime}$ & None & 61 & 49 & - & $\begin{array}{l}\text { MD } \mathbf{0 . 2 1} \\
\text { increase (0.04 } \\
\text { decrease to- } \\
0.46 \text { increase) }\end{array}$ & $\begin{array}{l}\oplus \circ \circ \bigcirc \\
\text { Very low }\end{array}$ & Important \\
\hline \multicolumn{13}{|c|}{ Complications (including drug adverse effects/safety issues/hospital stay period) (hyperkalemia) } \\
\hline 1 & $\mathrm{RCT}$ & ${ }_{c}^{\text {Serious }}$ & Not serious & Not serious & $\underset{n}{\text { Serious }}{ }^{m}$ & None & $\begin{array}{l}0 / 30 \\
(0.0 \%)\end{array}$ & $\begin{array}{l}0 / 15 \\
(0.0 \%)\end{array}$ & $\begin{array}{l}\text { Cannot } \\
\text { estimate }\end{array}$ & $\begin{array}{l}\text { No change } \\
\text { per } 1000 \\
\text { patients (100 } \\
\text { patients }\end{array}$ & $\begin{array}{l}\oplus \oplus \circ \circ \\
\text { Low }\end{array}$ & Important \\
\hline
\end{tabular}


Table 3 Evidence profile: SR1.1. Comparison of ACEI and ARB with other drugs (Continued)

\begin{tabular}{|c|c|c|c|c|c|c|c|c|c|c|c|c|}
\hline \multicolumn{7}{|c|}{ Certainty assessment } & \multicolumn{2}{|c|}{$\begin{array}{l}\text { Number of } \\
\text { patients }\end{array}$} & \multicolumn{2}{|l|}{ Effect } & \multirow[t]{2}{*}{ Certainty } & \multirow[t]{2}{*}{ Importance } \\
\hline $\begin{array}{c}\text { No. of } \\
\text { studies }\end{array}$ & $\begin{array}{l}\text { Study } \\
\text { design }\end{array}$ & $\begin{array}{l}\text { Bias } \\
\text { risk }\end{array}$ & Inconsistency & Indirectness & Inaccuracy & Other & $\begin{array}{l}\text { ARB, } \\
\text { ACEI }\end{array}$ & $\begin{array}{l}\text { Other } \\
\text { drugs }\end{array}$ & $\begin{array}{l}\text { Relative } \\
{[95 \% \mathrm{Cl}]}\end{array}$ & $\begin{array}{l}\text { Absolute } \\
(95 \% \mathrm{Cl})\end{array}$ & & \\
\hline & & & & & & & & & & $\begin{array}{l}\text { decreased to } \\
100 \text { patients } \\
\text { increased) }\end{array}$ & & \\
\hline \multicolumn{13}{|c|}{ Complications (including drug adverse effects/safety issues/hospital stay period) (hospitalization) } \\
\hline 1 & $\mathrm{RCT}$ & $\begin{array}{l}\text { Not } \\
\text { serious }\end{array}$ & Not serious & Serious $^{\circ}$ & Serious $^{p}$ & None & $\begin{array}{l}14 / 30 \\
(46.7 \%)\end{array}$ & $\begin{array}{l}13 / 30 \\
(43.3 \%)\end{array}$ & $\begin{array}{l}\text { Cannot } \\
\text { estimate }\end{array}$ & $\begin{array}{l}30 \text { patients } \\
\text { decreased } \\
\text { per } 1000 \\
\text { patients ( } 280 \\
\text { patients } \\
\text { decreased to } \\
220 \text { patients } \\
\text { increased) }\end{array}$ & $\begin{array}{l}\oplus \oplus \circ O \\
\text { LoW }\end{array}$ & Important \\
\hline \multicolumn{13}{|c|}{ Other outcomes deemed important by the CQ team (cardiovascular events) } \\
\hline 2 & $\mathrm{RCT}$ & $\begin{array}{l}\text { Not } \\
\text { serious }\end{array}$ & Not serious & Not serious & Serious ${ }^{a}$ & None & $\begin{array}{l}5 / 48 \\
(10.4 \%)\end{array}$ & $\begin{array}{l}5 / 46 \\
(10.9 \%)\end{array}$ & $\begin{array}{l}\text { Cannot } \\
\text { estimate }\end{array}$ & $\begin{array}{l}\text { No change } \\
\text { per } 1000 \\
\text { patients ( } 90 \\
\text { patients } \\
\text { decreased to } \\
90 \text { patients } \\
\text { increased) }\end{array}$ & $\begin{array}{l}\oplus \oplus \oplus \bigcirc \\
\text { Moderate }\end{array}$ & Critical \\
\hline
\end{tabular}

$C l$, confidence interval; $R R$, risk ratio; $M D$, mean difference; $R C T$, randomized clinical trial

${ }^{a}$ Many unclear elements. About half of the included studies are at high risk of having incomplete outcome data

${ }^{b}$ If considering $1 \%$ of risk difference as the clinical decision threshold, the $95 \% \mathrm{Cl}$ of risk difference crosses the threshold

'There is an unignorable bias in the studies with high weight

${ }^{d}$ If considering $2 \%$ of risk difference in PD technical failure as the clinical decision threshold, the $95 \% \mathrm{Cl}$ of risk difference crosses the threshold

eDue to the definition of peritonitis as a cause of technical survival

f If considering $2 \%$ of risk difference in the PD peritonitis rate as the clinical decision threshold, the $95 \% \mathrm{Cl}$ of risk difference crosses the threshold

gIf considering $100 \mathrm{ml}$ of urine volume difference as the clinical decision threshold, the $95 \% \mathrm{Cl}$ of mean difference crosses the threshold

$\mathrm{h}_{\text {If }}$ considering $5 \%$ of risk difference in the anuria rate as the clinical decision threshold, the $95 \% \mathrm{Cl}$ of risk difference crosses the threshold

'There are unignorable biases in allocation concealment and incomplete data in two studies

${ }^{j}$ If considering $1.0 \mathrm{ml} / \mathrm{min}$ of GFR difference as the clinical decision threshold, the $95 \% \mathrm{Cl}$ of mean difference crosses the threshold

${ }^{\mathrm{k}}$ Total $\mathrm{Kt} / \mathrm{V}$ is the sum of residual renal and peritoneal urea clearance and therefore does not indicate peritoneal membrane function

IIf considering 0.1 of a total $\mathrm{Kt} / \mathrm{N}$ difference as the clinical decision threshold, the $95 \% \mathrm{Cl}$ of mean difference crosses the threshold

$\mathrm{m}_{\text {The low number of events }}$

${ }^{n}$ If considering $5 \%$ of risk difference in hyperkalemia as the clinical decision threshold, the $95 \% \mathrm{Cl}$ of risk difference crosses the threshold

${ }^{\circ}$ Due to the definition of hospitalization as a complication

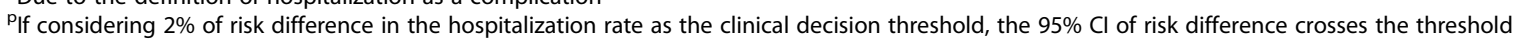

${ }^{\mathrm{q}}$ If considering $2 \%$ of risk difference in cardiovascular events as the clinical decision threshold, the $95 \% \mathrm{Cl}$ of risk difference crosses the threshold

or not their residual renal function is being maintained. With regard to values (and intentions), we have determined that pressing issues of uncertainty or significant sources of variance most likely do not exist.

In terms of critical outcomes (i.e., total mortality, technical survival, and cardiovascular events), all studies had rather short observation periods of between 1 and 2 years in length. Consequently, the number of events was low, no differences were observed between the groups, and any effects of the interventions used remained unclear. Thus, we considered residual renal function including urine volume in our CPG panel. This was related to both patient prognosis and quality of life (QOL) as critical outcomes, and it could therefore be used in the judgment of recommendations. The intervention increased the mean difference of urine volume by $142.5 \mathrm{~mL}$, and the lower limit of the $95 \% \mathrm{CI}$ by $25.42 \mathrm{~mL}$. Although there was no statistical difference, we assessed that the intervention was probably superior based on the result of the reduction of the relative risk of anuria to 0.70 [95\% CI; 0.46-1.02]. Additionally, a study in subgroup analyses evaluating ACEI (Li 2003 [8], see Additional file 1: Appendix 6.1.2) had a low risk of bias. Despite the existence of only one study, a post-intervention mean difference in the GFR of 0.72 [0.52-0.90] allowed us to assess that an effect was present. With regard to ARB, we assessed that intervention with RAS inhibitors was superior based on our judgment that an effect existed for preserving urine volume and GFR.

In terms of cost, the patient need not pay for these interventions under the Japanese insurance system. From the perspective of rising healthcare costs, inexpensive generic alternatives for both ACEI and ARB have circulated widely throughout the market. We also do not believe cost to be much of an issue in this particular case. 


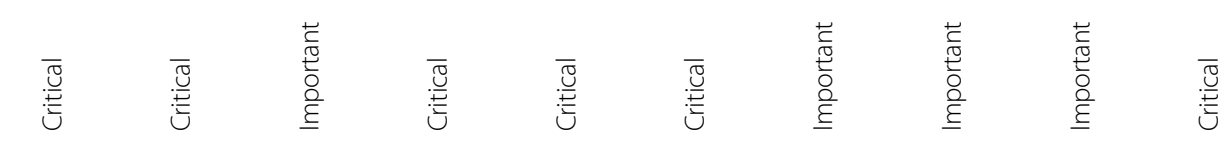

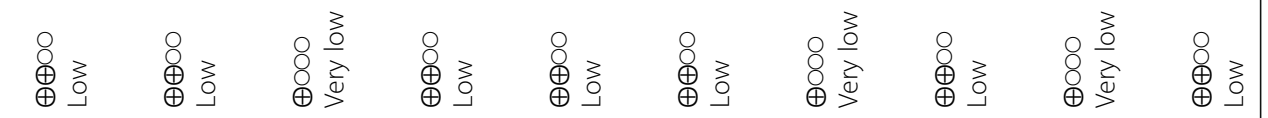

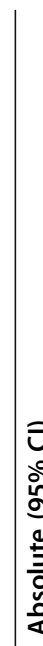

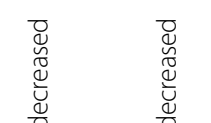
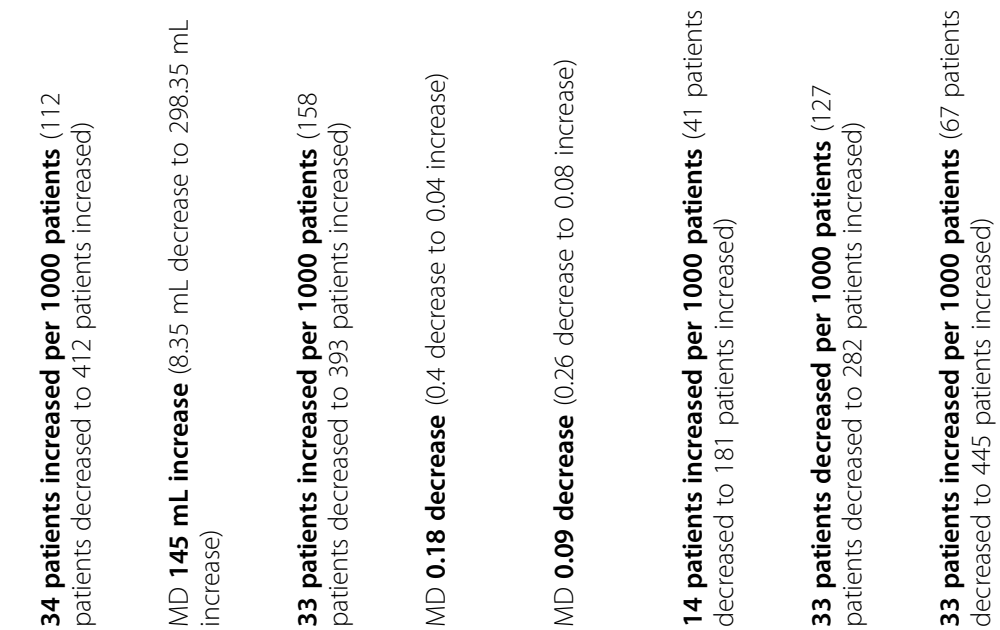

总

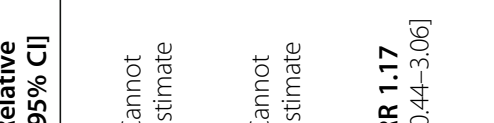

पب

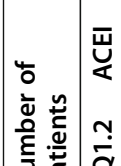

प्र

ஓ̊̀

透

ㅇํㅇ.

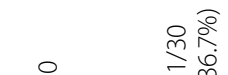

命

m̊

8寒

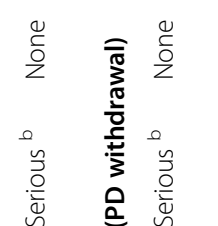

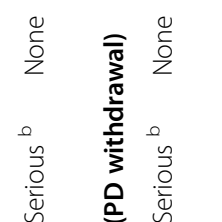

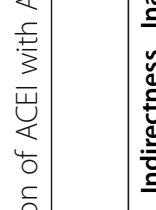

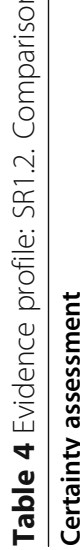

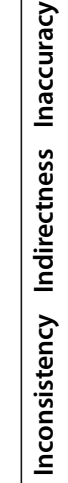

氖

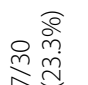

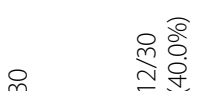
然

$\frac{2}{2}$

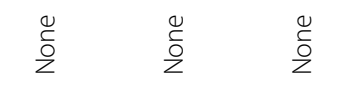

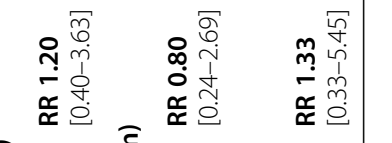

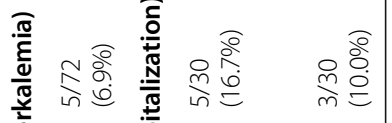

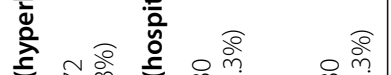

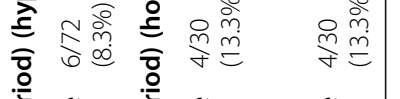

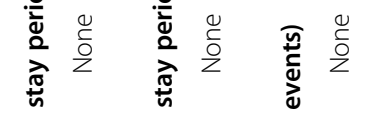

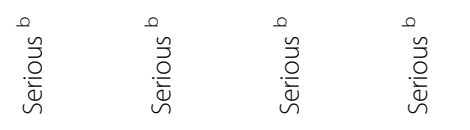

and

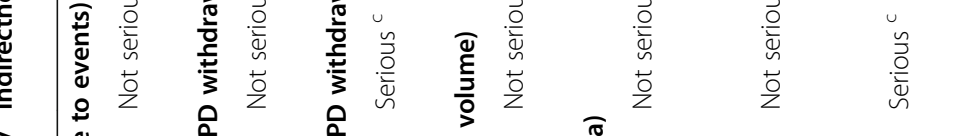

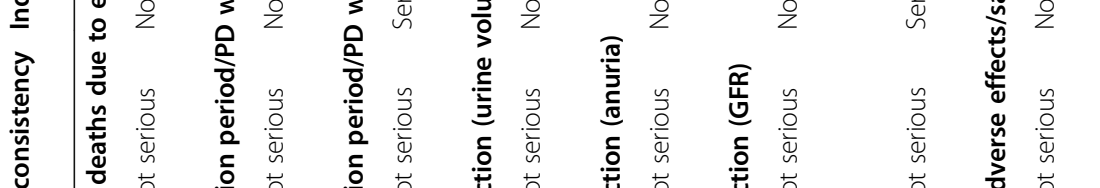

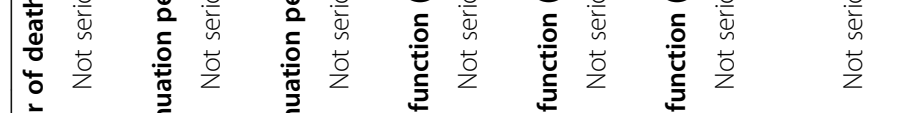

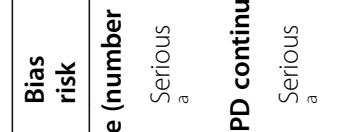

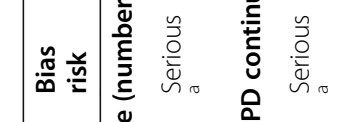

突

售

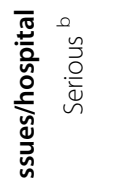

产

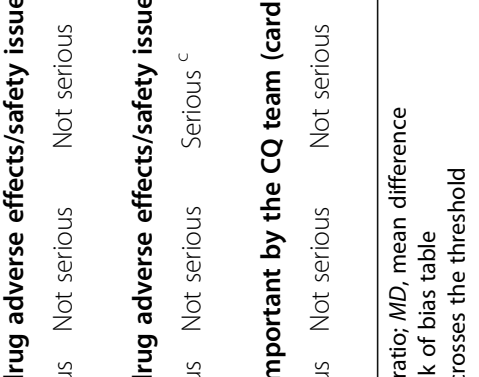

䇏咅 
CQ2: Icodextrin or glucose solution: which is more useful as a dialysate among patients with PD?

\section{Recommendation}

When it comes to the management of body fluid in PD patients, we suggest the use of icodextrin (GRADE 2C).

\section{About this CQ}

In the management of $\mathrm{PD}$, peritoneal ultrafiltration volume and residual renal function are very important factors that relate to body fluid management and PD continuation period. The icodextrin dialysis solution does not use glucose as an osmotic agent. Because it is a high molecular weight glucose polymer, it is very difficult for it to be absorbed through the peritoneum. Therefore, it has superior ultrafiltration effects as a dialysis solution. In particular, in patients categorized as high transporter in peritoneal equilibrium tests, icodextrin dialysis solution was effective even in cases with poor clearance with the glucose dialysis solution. This was highly useful for fluid management associated with continuation of PD. Conversely, there were concerns about lowering residual renal function as well as the occurrence of rashes. In Japan, the icodextrin dialysis solution entered the market in 2003. Despite the 15 years that have passed since then, in the most current version of PD guidelines for Japan (published in 2009), it has not been discussed. Here, we have carried out a systematic review of the benefits and adverse effects of icodextrin dialysis solution vs. glucose dialysis solution monotherapy.

\section{Basis of judgment}

With regard to the effectiveness of icodextrin dialysate (interventional group) compared to the glucose dialysis solution monotherapy (control group), allcause mortality had a risk ratio (RR) of 0.75 [0.331.71]. Among 1000 patients under study, the number of mortalities decreased by seven patients (18 patients decreased to 19 patients increased); thus, no significant difference was observed. However, icodextrin therapy had the superior point estimate. Next, with regard to episodes of uncontrolled fluid overload (judged to be an important outcome), the icodextrin group had an RR of 0.31 [0.12-0.82]. Among 1000 patients, the number of those with episodes decreased by 73 , suggesting a significant superiority of the icodextrin group. While a significant difference was also not observed for peritoneal ultrafiltration volume, the icodextrin group had larger values. Ultimately, the icodextrin group had fewer withdrawals for technical survival, and an RR of 0.57 [0.29-1.12]. Among 1000 patients, the withdrawals decreased by 32 patients ( 9 patients increased to 52 patients decreased). Thus, the result itself was quite good while no significant difference was observed. Conversely, a reduction in urine volume and a loss of residual renal function were not observed with an increase in peritoneal ultrafiltration volume. In our CPG panel, it was pointed out that in this evidence, the outcome resulted in poor body fluid management. Furthermore, it would be better if we limited our recommendations to patients with poor body fluid management even though the evidence did not only target patients with poor body fluid management. Conversely, the opinion was also emerged that it may be possible to perform body fluid management with only highly concentrated glucose solutions. Ultimately, we decided to append "When it comes to the management of body fluid in PD patients" to our recommendation and to take care to prevent the incorporation of excessive use protocols such as ones in which the icodextrin dialysis solution was used for all patients.

Additionally, while peritoneal function was determined to be a critical outcome in our panel committee meeting, the importance of various outcomes was further discussed. Peritoneal function was judged to be next to the overall survival rate and technical survival, which was of comparatively low importance. Thus, this outcome was downgraded to an important status at the time of the CPG panel meeting.

With regard to adverse effects, peritonitis had an RR of 0.95 [0.79-1.15], and a difference was not observed between the interventional group and the control group. For rashes, the RR was 1.84 [0.48-7.09], and point estimates revealed that the intervention group had more occurrences, although a significant difference was not observed. However, most of these rashes were described in studies that were conducted soon after the icodextrin dialysis solution was introduced into the market (Wolfson 2002 [9], Finkelstein 2005 [10], see Additional file 1: Appendix 6.2.2). In comparatively newer reports (Lin 2009a [11], Chang 2016 [12], see Additional file 1: Appendix 6.2.2), these occurrences have clearly decreased in frequency, and they occurred at virtually the same rate as that associated with the glucose dialysis solution. A recent study by Baxter International showed that of 537 patients, in whom icodextrin dialysis solution was used, 27 (5\%) developed rashes and eight (1.5\%) developed exfoliative dermatitis. A response by Terumo indicated that since their product went on sale in December 2014, only one case of whole-body exfoliative dermatitis occurred in 2015, a decidedly small percentage. A case report by Nanamatsu et al. on icodextrin dialysis solution allergies also indicated that they occur most often between 7 and 10 days after beginning the treatment, and nearly all cases resolve quickly after stopping treatment [13]. From the above, 
we determined that the occurrence of undesirable effects due to the use of icodextrin dialysis solution is by no means common.

Aside from this, no variance in values was observed. Similarly, there is no difference between these treatments in terms of the cost borne by the patient under Japanese healthcare insurance, and we therefore believe the choice to have little financial impact.

Consequently, we have assessed that in terms of effect, the use of icodextrin dialysis solution is superior to that of glucose dialysis solution monotherapy (Table 5).

\section{CQ3: Is it better to apply or not apply mupirocin/ gentamicin ointment to the exit site? Recommendation}

We suggest not applying mupirocin/gentamicin ointment to the exit sites of PD patients (GRADE 2C).

\section{About this CQ}

Peritonitis is a common reason for early withdrawal from PD treatment. In order for the patient to continue their PD treatment in a stable manner, it is important to prevent peritonitis and exit site infection, which is the most common cause of peritonitis. In western countries, application of antibiotic ointment to the exit site is often recommended. However, neither mupirocin nor gentamicin ointment is covered by insurance in Japan. Existing guidelines and SRs on the effect of mupirocin ointment on exit site infections and peritonitis include investigations where application of mupirocin to the exit site has been grouped together with the application to the nasal cavity, researches on patients who carry Staphylococcus bacteria in their nasal cavity, and observational trials in addition to RCTs. In this CQ, we examined whether the application of mupirocin ointment or gentamicin ointment is superior to not applying any kind of antibiotic ointment to the exit site for preventing exit site infection. Additionally, we looked exclusively at RCTs that targeted all PD patients, who do and do not carry bacteria in their nasal cavity, to determine whether mupirocin or gentamicin is better at preventing infection.

\section{Basis of judgment}

Under the International Society for Peritoneal Dialysis (ISPD) recommendations for peritonitis, the 2016 version on prevention and treatment strongly recommends mupirocin administration because the systematic reviews listed in the ISPD recommendation also indicated that mupirocin was evidently very effective. In these systematic reviews, nasal cavity application and observational studies showed that mupirocin administration was highly effective (see Additional file 1: Appendix). However, the SR of the results of RCTs on exit site application in this guideline showed that the effect of mupirocin administration was far smaller than that evaluated in ISPD recommendations. In a comparison between applications of mupirocin ointment to the exit site and controls, mupirocin ointment was superior in terms of point estimates of all outcomes. Conversely, no significant differences were observed between the two drugs in any of the outcomes in a comparison of mupirocin and gentamicin ointments. At our panel meetings, these results were highlighted as evidence that implementation of the antibiotics application in Japan may improve treatment results.

After collecting a great deal of evidence about the adverse effects of these treatments, the issue of the emergence of resistant bacteria due to long-term usage of antibiotic ointments arose in our CPG panel meetings. To date, the mupirocin resistance rates of MRSA following mupirocin ointment use have been reported at 2.2 to $81 \%$. Additionally, gentamicin resistance rates of 17.7 to $70.9 \%$ have already been observed in skin and soft tissue infections. Thus, long-term use of either of these treatments results in fear of the appearance or increase of resistant strains.

The PD peritonitis incidence in Japan is 0.20 events/ patient-year [14], lower than the figure cited in the ISPD recommendations (0.50). Even if application of mupirocin or gentamicin ointment is effective in western countries, current exit site management protocols in use in Japan which do not involve the application of antibiotic ointments may even be said to be superior than those in many other countries, leading us to believe that there is not much benefit to be gained from their application. Furthermore, considering the cost and issue of antibiotic resistance, we have decided on a recommendation that suggests that mupirocin/gentamicin ointment not be applied. Finally, preventative application of mupirocin and gentamicin ointment to the exit site is not covered by insurance (Tables 6 and 7).

\section{CQ4: When a PD catheter is placed, which surgical approach is desirable, open surgery or laparoscopic surgery? \\ Recommendation \\ No recommendation.}

\section{About this CQ}

The performance of an appropriate catheter placement surgery is a prerequisite for the smooth implementation of PD. There are three methods used to insert a catheter: open surgery, laparoscopic surgery, and percutaneous insertion. There are no available devices for percutaneous catheter insertion in Japan, so either open or laparoscopic surgery is practiced in most facilities. Laparoscopic procedures generally require a smaller incision in 


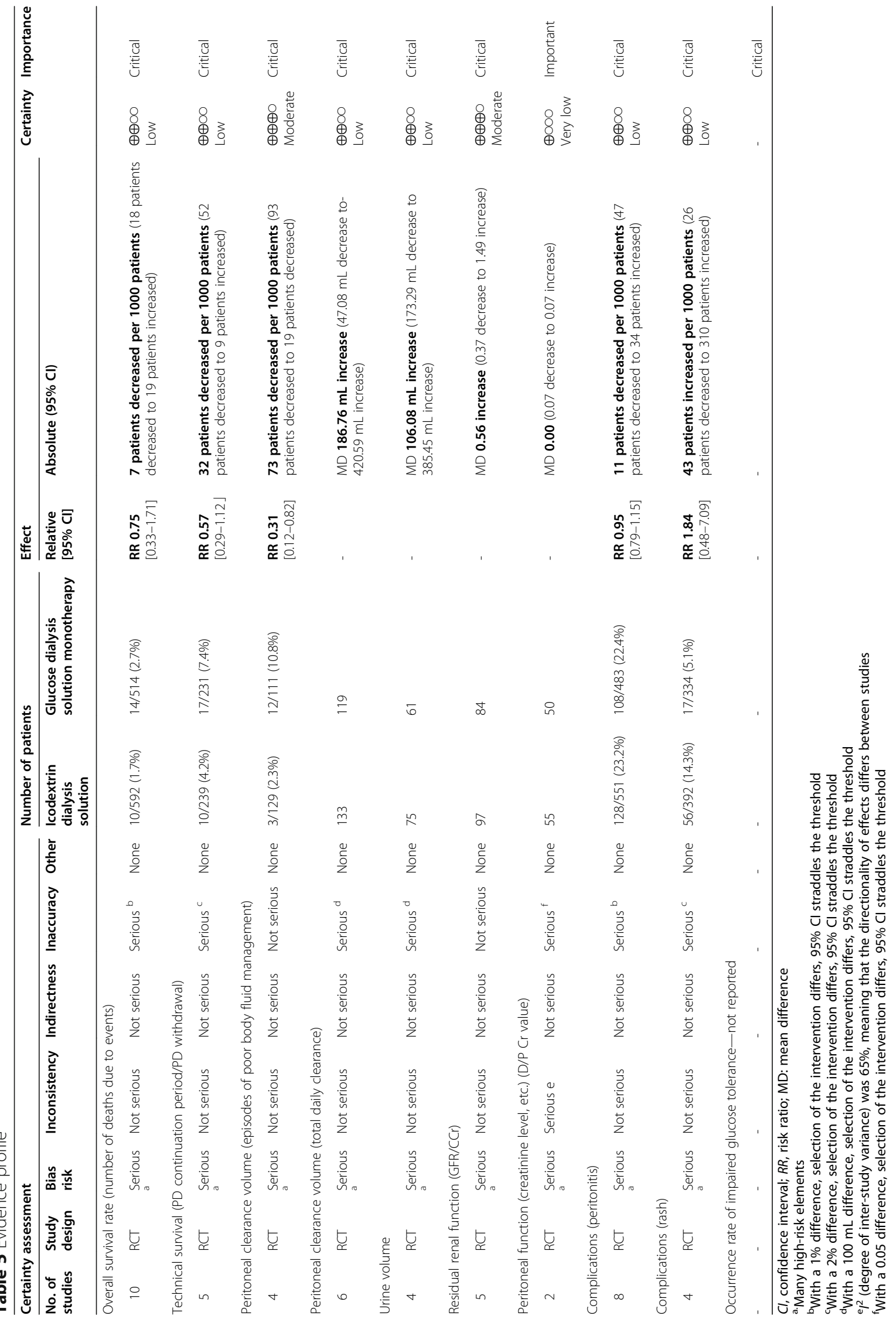




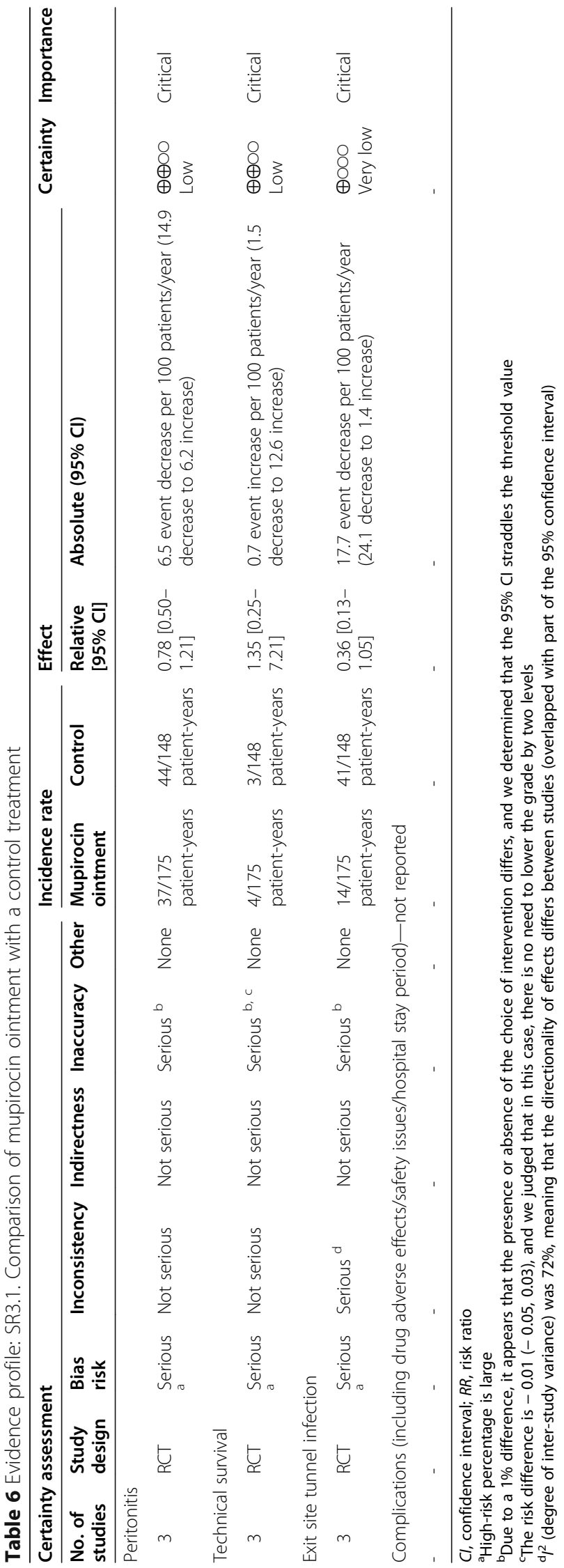




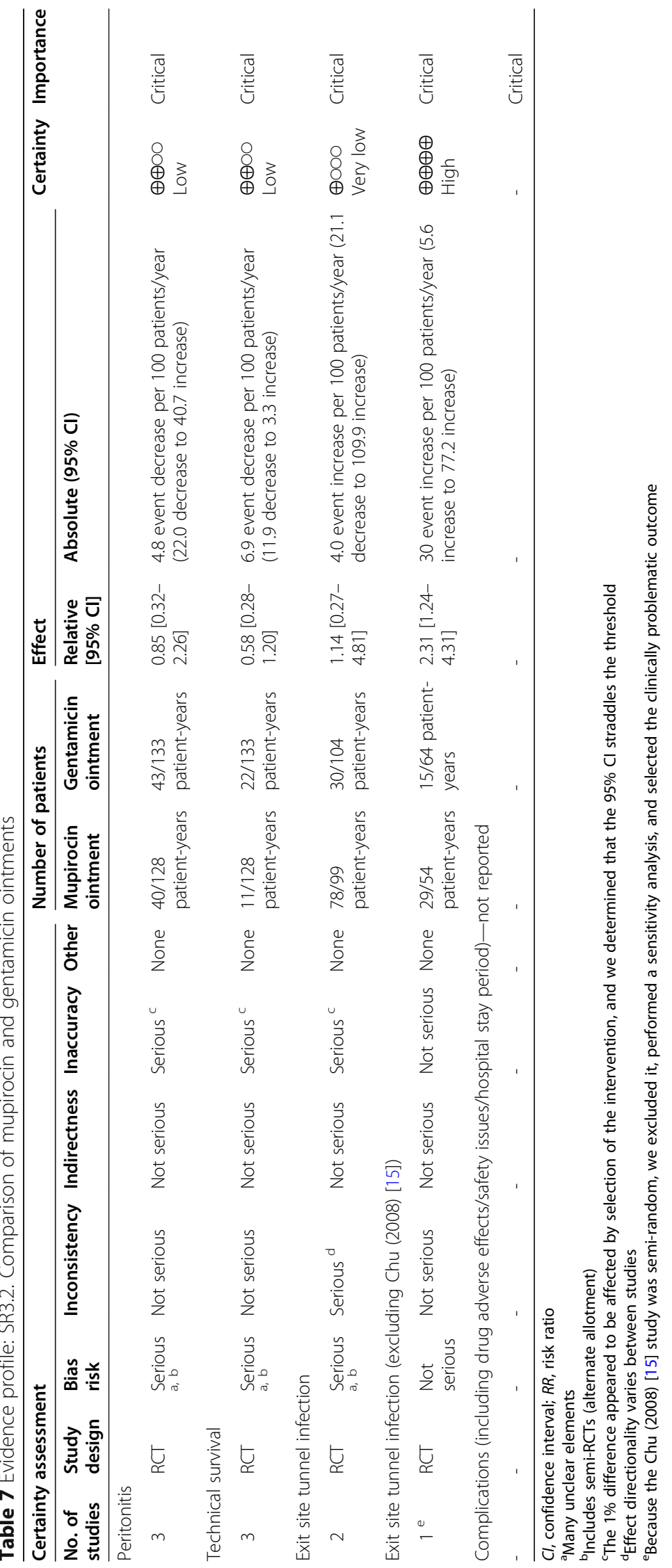


the skin than open procedures, thereby leaving smaller scar, and are also less painful than open surgeries after the procedure. Its most significant benefits are shorter postoperative recovery periods and hospital stays and that patients can return to their daily activities quicker. Additional merits of laparoscopic surgery include the following: the surgeon can insert the catheter while directly observing its tip as it goes in; procedures to prevent catheter coiling, like omentopexies and omentectomies, can be performed; the ability to prevent catheter migration by securing the catheter inside the abdominal cavity; additional procedures, such as adhesiolysis for patients with abdominal cavity adhesion, can be performed; and hernia repair surgeries can be simultaneously performed on patients with inguinal hernias. However, the increased risk of complications unique to laparoscopic surgery include increased cost due to a need for general anesthesia, specialized equipment and particular facilities, the need for a well-versed surgeon in laparoscopic procedures, organ damage that may occur during trocar insertion, bleeding that may occur on removal, subcutaneous emphysema or gas embolism/pulmonary embolism associated with pneumoperitoneum, and organ damage due to limited vision. While several studies have compared the postoperative outcome of open and laparoscopic surgery, the total number of cases investigated is rather low, and there is not enough evidence as to which of the two methods is superior. Thus, we selected this CQ since we noticed that there is a need to clarify which catheter insertion surgery is better.

\section{Basis of judgment}

The survival rate for laparoscopic surgery compared to open surgery had an RR of 1.07 [0.98-1.16] (low evidence certainty). Additionally, the relative risk of catheter migration in laparoscopic surgery compared to the open approach was 0.42 [0.18-0.96] (moderate evidence certainty). The RR was 0.99 [0.43-2.29] for exit site and tunnel infections (low evidence certainty). Because the only analysis in which a statistically significant difference was found included studies in which the catheter was anchored inside the abdominal cavity, we carried out a subgroup analysis on the presence or absence of catheter anchoring. Significantly fewer incidences of catheter migration occurred in laparoscopic procedures with catheter anchoring than in open procedures (RR 0.09 [0.01-0.68]). However, we found no significant difference between laparoscopic procedures without catheter anchoring and open procedures (RR 0.58 [0.27-1.25]). Furthermore, only pain was evaluated with respect to QOL, and the certainty of that evidence was very low. From the above, we judged that there are some, albeit small, desirable effects associated with use of laparoscopic surgery. Regarding hospital stay duration, we found that open surgery was associated with shorter stays than laparoscopic surgery, but only two studies discussed this, and one of them, whose weighting was 91\% in the meta-analysis (Wright 1999 [16], see Additional file 1: Appendix 6.4.2), indicated an average hospitalization time of 2.4 days for open surgery and 3.1 days for laparoscopic surgery. These results differ greatly from those seen in Japan, and we decided not to use them as a basis for our judgment.

Conversely, in terms of adverse effects, early complications (presence of leaks) had an RR of 0.86 [0.25-3.02], and late complications (hernia) had an RR of 0.75 [0.212.72]. Additionally, while laparoscopic surgery requires general anesthesia, we considered it to be associated with nearly no adverse effects, and therefore, the undesirable effects arising from it were judged to be quite small.

Regarding patient preference for this $\mathrm{CQ}$, because open surgery can be performed under local or spinal anesthesia while laparoscopic surgery requires general anesthesia, the anesthesia-associated risk is higher for the latter procedure but it also involves less pain. However, because open procedures are also minimally invasive, it was pointed out in our CPG panel meetings that the merits of laparoscopic surgery are also quite small. As for cost, laparoscopic surgery for the purpose of PD catheter surgery is not covered by insurance in Japan. The cost of laparoscope use is borne by the facility in which it is used.

As indicated from our CPG panel meetings, the balance between the benefits and adverse effects of laparoscopic surgery is rather uncertain, and given the fact that in Japan, circumstances can differ greatly from facility to facility; we determined that a proactive recommendation or disrecommendation of laparoscopic surgery will only increase confusion in the clinical setting (Table 8). Thus, we have decided to put forth no recommendation on this issue.

\section{CQ5: Which administration route of antibiotics is better in PD patients with peritonitis, intravenous or intraperitoneal? \\ Recommendation}

We suggest intraperitoneal administration of antibiotics in PD patients who have developed peritonitis (GRADE 2C).

Note: The national insurance does not currently cover intraperitoneal administration.

\section{About this CQ}

The main objectives of this CQ are (1) to clarify the superiority or inferiority of intraperitoneal administration in comparison with intravenous administration and (2) to clarify whether continuous or intermittent intraperitoneal administration is better. 


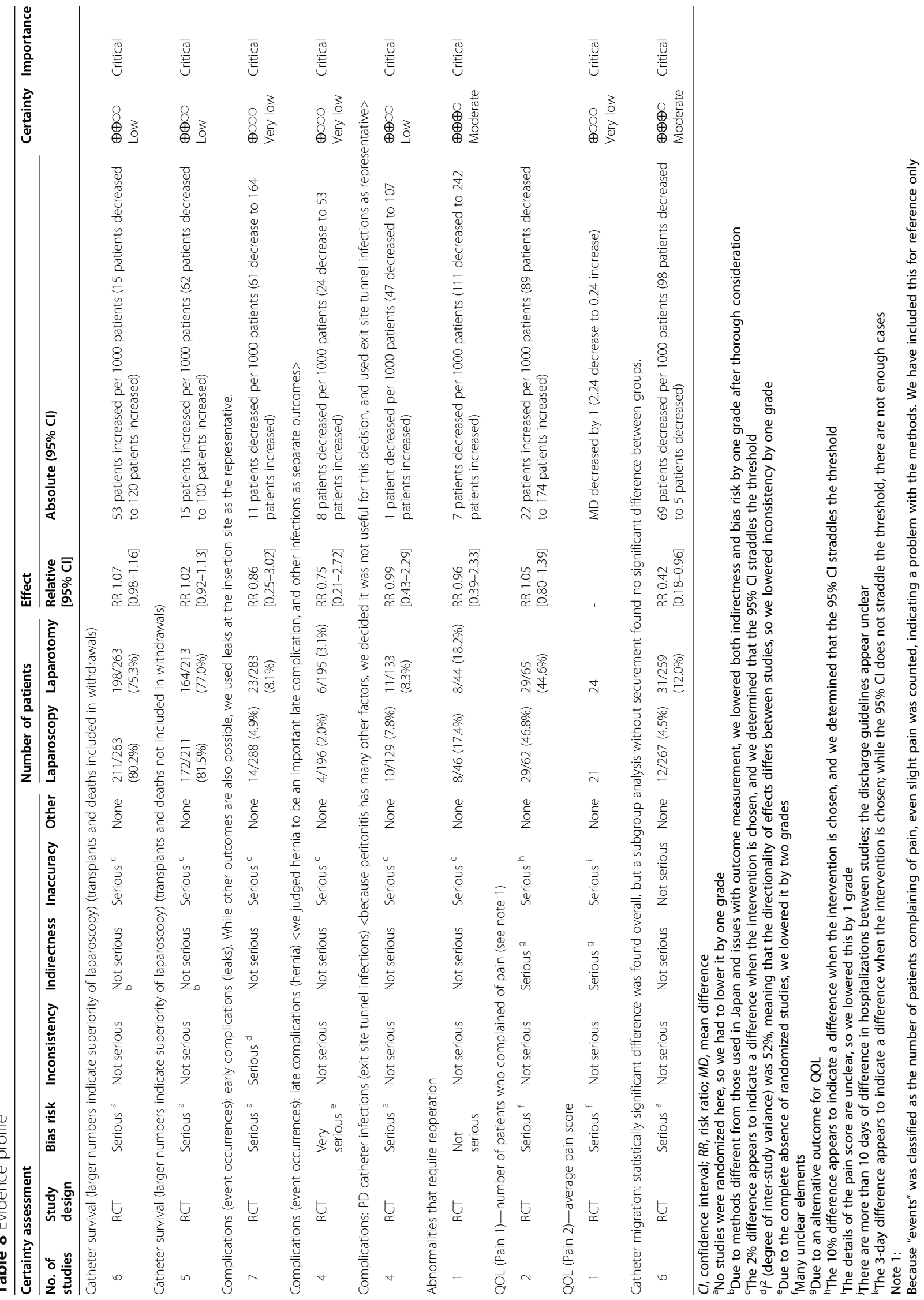




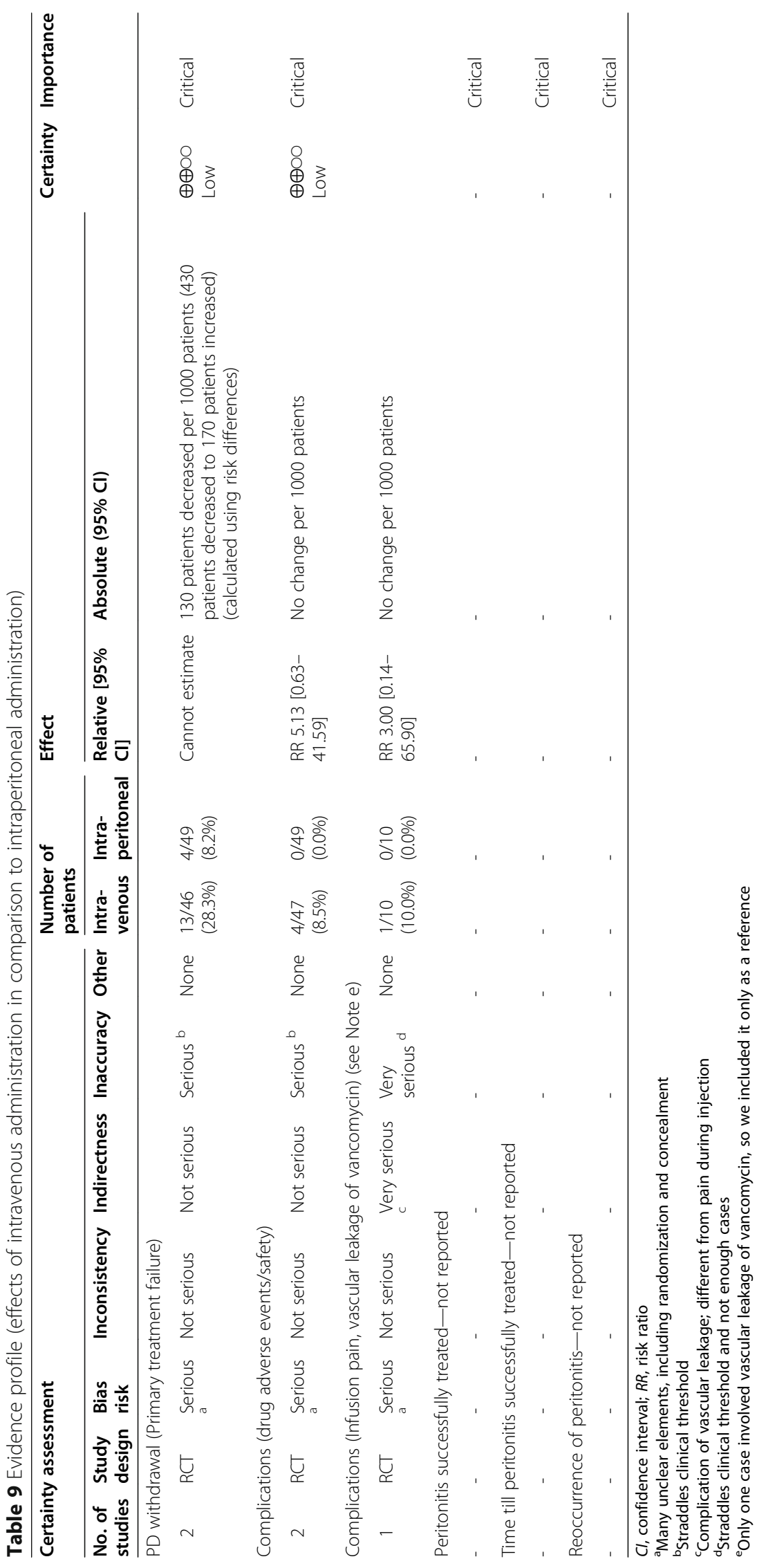


However, after conducting a literature search in accordance with a process that is discussed below, we found that the two RCTs that were suitable for analysis contained data that could not present a valid answer to the second question above. Specifically, one of the papers [17] used both vancomycin (VCM) and tobramycin (TOB) in both groups, and compared intraperitoneal continuous administration (VCM $20 \mathrm{mg} / \mathrm{L}+\mathrm{TOB} 4 \mathrm{mg} /$ $\mathrm{L}$ mixed into each $\mathrm{PD}$ bag) and daily administration (VCM 0.5 or $1.0 \mathrm{~g}+$ TOB $1.0 \mathrm{mg} / \mathrm{kg}$ BW given as intravenous injection once daily). The other study [11] compared intraperitoneal and intravenous initial VCM administration (loading dose; $1 \mathrm{~g} / \mathrm{body}$ ); after initial treatment in both groups, the patients received intraperitoneal VCM $(25 \mathrm{mg} / \mathrm{L})$. Based on these reasons, we decided that answering second question of CQ5 was not possible.

Both groups received the same intraperitoneal VCM regimen after initial dosage in the latter study [18]. Therefore, it may be thought that the control group cannot be considered to have undergone "intravenous administration." However, we judged that increasing the number of patients covered by our analysis was of great benefit here, so we incorporated this study and attempted to answer first question of CQ5.

\section{Basis of judgment}

Despite the lack of a statistically significant difference in PD withdrawal, based on the fact that intraperitoneal administration caused a decrease of 130 patients/1000 patients (430 decreased to 170 increased), and given that there are no reports that indicate that it has more adverse effects than intravenous administration, we judged the intervention (intraperitoneal ) to be superior (Table 9).

However, when the lack of insurance coverage for intraperitoneal administration is taken into account, as well as the fact that the benefits of antibiotics other than VCM have not been clarified, we decided that at present, it is prudent to issue this recommendation with certain conditions attached. Additionally, many facilities are now already practicing intraperitoneal administration of antibiotics following the ISPD guidelines. For this reason, we decided to weakly recommend the procedure instead of not recommending it. Of course, this recommendation does not negate or reject intravenous administration. At our CPG panel meetings, an opinion was put forth that the addition of insurance coverage for intraperitoneal administration is necessary, especially in the case of future at-home PD treatment.

\section{CQ6: Is PD or HD better as the first renal replacement therapy in diabetic patients? Recommendation}

No recommendation.

\section{About this $C Q$}

While there are many studies that consider the relative merits of HD and PD in patients with diabetes, almost all of them are observational studies, and various results have been reported. The only one RCT [19] targets a population with a mixture of diabetic and non-diabetic patients. There are no analysis of diabetes patients alone. Consequently, we had to carry out our SR of diabetes patients using observational studies.

\section{Basis of judgment}

Because these studies are all observational, both the risk of bias and the possibility that adjustment for confounding factors was insufficient are serious. For this reason, the quality of the evidence was downgraded to "very low." Of the papers we considered here, many cited a low mortality for HD (Table 10). It was pointed out that at the very least, there is no evidence actively supporting PD. In addition, no studies have compared urine volume, residual renal function, and glycemic control. All the studies examined here were unclear regarding the details of their treatment conditions (type of dialysis solution, etc.) and research subjects (age, etc.). In particular, the treatment methods of HD varied greatly. Thus, we ultimately determined in our CPG panel meetings that we are unable to issue a recommendation on this matter.

Table 10 Evidence profile

\begin{tabular}{|c|c|c|c|c|c|c|c|c|c|}
\hline \multicolumn{7}{|c|}{ Certainty assessment } & \multirow{2}{*}{ Effect } & \multirow[t]{2}{*}{ Certainty } & \multirow[t]{2}{*}{ Importance } \\
\hline $\begin{array}{l}\text { No. of } \\
\text { studies }\end{array}$ & Study design & $\begin{array}{l}\text { Bias } \\
\text { risk }\end{array}$ & Inconsistency & Indirectness & Inaccuracy & $\overline{\text { Other }}$ & & & \\
\hline \multicolumn{10}{|l|}{ Death } \\
\hline 16 & $\begin{array}{l}\text { Observational } \\
\text { studies }\end{array}$ & Serious & Serious & Not serious & Not serious & None & $\begin{array}{l}\mathrm{HD} \text { is better: } 9 \\
\text { reports } \\
\text { PD is better: } 2 \text { reports }\end{array}$ & $\begin{array}{l}\oplus \circ 0 \bigcirc \\
\text { Very low }\end{array}$ & Critical \\
\hline
\end{tabular}




\section{Abbreviations}

ACEl: Angiotensin-converting enzyme inhibitors; ARB: Angiotensin receptor blockers; CPG: Clinical practice guidelines; CQ: Clinical question; HD: Hemodialysis; JSDT: Japanese Society for Dialysis Therapy; PD: Peritoneal dialysis; PDOPPS: Peritoneal Dialysis Outcomes and Practice Patterns Study; RAS: Renin-angiotensin system; SR: Systematic reviews

\section{Supplementary Information}

The online version contains supplementary material available at https://doi. org/10.1186/s41100-021-00361-9.

Additional file 1. Peritoneal dialysis guidelines 2019. Part 2: Appendix.

\section{Acknowledgements}

We acknowledge the panel members for discussing and deciding the recommendations and outcomes, the external evaluating members for qualifying and suggesting this $\mathrm{GL}$, and the librarians for searching literature.

\section{Authors' contributions}

Yasuhiko Ito: Final approval of the article. Hidetomo Nakamoto: Critical revision of the article for important intellectual content and final approval of the article. Yuichi Ishikawa: Critical revision of the article for important intellectual content and final approval of the article. Noritomo Itami: Critical revision of the article for important intellectual content and final approval of the article. Minoru Ito: Analysis and interpretation of the data, critical revision of the article for important intellectual content, and final approval of the article. Atsushi Ueda: Analysis and interpretation of the data, critical revision of the article for important intellectual content, and final approval of the article. Yoshie Kanazawa: Analysis and interpretation of the data, critical revision of the article for important intellectual content, and final approval of the article. Hideki Kawanishi: Analysis and interpretation of the data, critical revision of the article for important intellectual content, and final approval of the article. Yoshihiko Kanno: Analysis and interpretation of the data, critical revision of the article for important intellectual content, and final approval of the article. Hitoshi Sugiyama: Analysis and interpretation of the data, critical revision of the article for important intellectual content, and final approval of the article. Kazuhiko Tsuruya: Analysis and interpretation of the data, critical revision of the article for important intellectual content, and final approval of the article. Hiroyuki Terawaki: Analysis and interpretation of the data, critical revision of the article for important intellectual content, and final approval of the article. Tadashi Tomo: Analysis and interpretation of the data, critical revision of the article for important intellectual content, and final approval of the article. Mizuya Fukasawa: Analysis and interpretation of the data, critical revision of the article for important intellectual content, and final approval of the article. Akihiro C. Yamashita: Analysis and interpretation of the data, critical revision of the article for important intellectual content, and final approval of the article. Hideki Yokoi: Analysis and interpretation of the data, critical revision of the article for important intellectual content, and final approval of the article. Masaaki Nakayama: Analysis and interpretation of the data, critical revision of the article for important intellectual content, and final approval of the article. Hidemichi Yuasa: Analysis and interpretation of the data; administrative, technical, and logistic support; critical revision of the article for important intellectual content; and final approval of the article. Yasushi Tsujimoto: Analysis and interpretation of the data; administrative, technical, and logistic support; critical revision of the article for important intellectual content; and final approval of the article. Hiraku Tsujimoto: Analysis and interpretation of the data; administrative, technical, and logistic support; critical revision of the article for important intellectual content; and final approval of the article. Yosuke Saka: Analysis and interpretation of the data, drafting of the article, and final approval of the article. Yusuke Kuroki: Analysis and interpretation of the data, drafting of the article, and final approval of the article. Kaoru Yasuda: Analysis and interpretation of the data, drafting of the article, and final approval of the article. Takayuki Fujii: Analysis and interpretation of the data, drafting of the article, and final approval of the article. Atsuhiro Kanno: Analysis and interpretation of the data, drafting of the article, and final approval of the article. Emi Fujikura: Analysis and interpretation of the data, drafting of the article, and final approval of the article. Kimio Watanabe: Analysis and interpretation of the data, drafting of the article, and final approval of the article. Yoko Obata: Analysis and interpretation of the data, drafting of the article, and final approval of the article. Miho Murashima: Analysis and interpretation of the data, drafting of the article, and final approval of the article. Naohiro Toda: Analysis and interpretation of the data, drafting of the article, and final approval of the article. Shuto Yamamoto: Analysis and interpretation of the data, drafting of the article, and final approval of the article. Yoshihiro Tsujimoto: Analysis and interpretation of the data, drafting of the article, and final approval of the article. Tsutomu Sakurada: Analysis and interpretation of the data, drafting of the article, and final approval of the article. Daisuke Komukai: Analysis and interpretation of the data, drafting of the article, and final approval of the article. Kiyotaka Uchiyama: Analysis and interpretation of the data, drafting of the article, and final approval of the article. Naoki Washida: Analysis and interpretation of the data, drafting of the article, and final approval of the article. Kohkichi Morimoto: Analysis and interpretation of the data, drafting of the article, and final approval of the article. Takahiro Kasai: Analysis and interpretation of the data, drafting of the article, and final approval of the article. Yukio Maruyama: Analysis and interpretation of the data, drafting of the article, and final approval of the article. Chieko Higuchi: Analysis and interpretation of the data, drafting of the article, and final approval of the article. Hiroaki lo: Analysis and interpretation of the data, drafting of the article, and final approval of the article. Keiichi Wakabayashi: Analysis and interpretation of the data, drafting of the article, and final approval of the article. Munekazu Ryuzaki: final approval of the article.

\section{Authors' information}

Working Group on Revision of Peritoneal Dialysis Guidelines of the

Japanese Society for Dialysis Therapy

Chairman: Yasuhiko Ito

Vice-Chairman: Munekazu Ryuzaki

President, Japanese Society for Dialysis Therapy: Hidetomo Nakamoto Working Group Members

Yuichi Ishikawa, Noritomo Itami, Minoru Ito, Atsushi Ueda, Yoshie Kanazawa, Hideki Kawanishi,

Yoshihiko Kanno, Hitoshi Sugiyama, Kazuhiko Tsuruya, Hiroyuki Terawaki, Tadashi Tomo, Hidetomo Nakamoto, Mizuya Fukasawa, Akihiro C. Yamashita and Hideki Yokoi

External Member (Japanese Society for Peritoneal Dialysis): Masaaki

Nakayama,

External Member: Hidemichi Yuasa.

Systematic Review Members

General:

Yasushi Tsujimoto, Hiraku Tsujimoto,

Clinical question (CO)1:

Ito Minoru*, Yosuke Saka, Yusuke Kuroki and Kaoru Yasuda.

CQ2:

Takayuki Fujii, Atsuhiro Kanno, Emi Fujikura and Kimio Watanabe.

CQ3:

Yoko Obata, Miho Murashima, Naohiro Toda, Shuto Yamamoto and Yoshihiro

Tsujimoto

CQ4:

Tsutomu Sakurada, Atsushi Ueda*, Daisuke Komukai and Kiyotaka Uchiyama. CQ5:

Hiroyuki Terawaki*, Naoki Washida, Kohkichi Morimoto and Takahiro Kasai. CQ6:

Yukio Maruyama, Chieko Higuchi, Hiroaki lo and Keiichi Wakabayashi.

*: Working Group Members

Panel Members

Masahito Tamura, Tadashi Tomo*, Hidetomo Nakamoto*, Tsutomu Furuzono,

Ikuto Masakane, Hiroya Masaki, Mamiko Matsumura, Masanobu Miyazaki,

Shinobu Tokumoto, Masayo Nogami and Yuko Mikami,

*: Working Group Members

External Evaluation members

Yoshihiro Toyoshima and Eishyu Nangou.

Literature Searching Librarian

Shinichi Abe, Chihiro Ishihara, Keika Hoshi and Mieko Mitani.

\section{Funding}

Literature surveys, conference expenses, transportation expenses, translation fee, etc., were paid for by financial support from the Japanese Society for Dialysis Therapy. 


\section{Availability of data and materials}

Please contact the author for data requests.

\section{Declarations}

\section{Ethics approval and consent to participate} Not applicable.

\section{Consent for publication}

Not applicable.

\section{Competing interests}

To ensure that the members of the working group can formulate with neutrality and transparency, the JSDT is showing commitment to avoid conflicts of interest (COI), either actual or presumed*.

All members of the working group and other committees must submit signed documents disclosing any potential or actual conflict of interest. These documents are updated annually, and the information within will be modified based on the circumstances. All this information is described in the "COI disclosures" below, and the JSDT secretariat keeps all supporting documentation.

Reference

${ }^{*}$ ) Japanese Society for Dialysis Therapy: Policy of Conflict of Interest in Medical Research. 2011: http://www.jsdt.or.jp/jsdt/1236.html

Yasuhiko Ito

Receives research funding, lecture fees, and other remuneration from or belongs to a department endowed by Baxter (imports, manufactures, and sells dialysis products, plasma protein formulations, and drug administration systems), Chugai Pharmaceutical Co. (manufactures, sells, imports, and exports prescription drugs), Kyowa Kirin Co. (manufactures and sells prescription drugs), Novartis (develops, imports, manufactures, and sells pharmaceuticals), and Teijin Pharma Ltd. (researches, develops, and manufactures pharmaceuticals and medical devices).

Munekazu Ryuzaki

Receives travel expenses for participating in academic conferences and other events from OMRON Corp. (manufactures and sells medical equipment). Noritomo Itami

Receives lecture fees and other remuneration from Kyowa Kirin Co. (manufactures and sells prescription drugs), Kissei Pharmaceutical Co. (researches, develops, manufactures, and sells pharmaceuticals), and Otsuka Pharmaceutical Co. (manufactures, sells, imports, and exports pharmaceuticals, clinical examinations, medical equipment, and food products).

Hideki Kawanishi

Receives lecture fees and other remuneration from Bayer Yakuhin Ltd. (develops, imports, manufactures, and sells pharmaceuticals, medical equipment, and veterinary drugs), Kissei Pharmaceutical Co. (researches, develops, manufactures, and sells pharmaceuticals), Terumo Corp. (manufactures and sells medical equipment and pharmaceuticals), Kyowa Kirin Co. (manufactures and sells prescription drugs), Nipro Corp. (manufactures and sells medical devices and pharmaceuticals), and Chugai Pharmaceutical Co. (manufactures and sells prescription drugs). Yoshihiko Kanno

Receives research funding, lecture fees, and writing fees from Kyowa Kirin Co. (manufactures and sells prescription drugs), Chugai Pharmaceutical Co. (manufactures, sells, imports, and exports prescription drugs), Fuji Pharma Co. (develops, manufactures, and sells pharmaceuticals), Kissei Pharmaceutical Co. (researches, develops, manufactures, and sells pharmaceuticals), Torii Pharmaceutical Co. (manufactures and sells pharmaceuticals), Sumitomo Dainippon Pharma Co. (manufactures and sells prescription drugs, diagnostic agents, and other products) Merck Sharp \& Dohme Corp. (develops, imports, manufactures, and sells pharmaceuticals, vaccines, and medical devices), and Igaku-Shoin Ltd. (publisher of medical books, magazines, and electronic media).

\section{Hitoshi Sugiyama}

Receives research funding from Sumitomo Dainippon Pharma Co. (manufactures and sells prescription drugs, diagnostic agents, and other products), Genzyme Corp. (imports, manufactures, and sells pharmaceuticals), and Bayer Yakuhin Ltd. (develops, imports, manufactures, and sells pharmaceuticals, medical devices, and veterinary drugs). Kazuhiko Tsuruya
Receives research funding, lecture fees, and other remuneration from or belongs to a department endowed by Chugai Pharmaceutical Co. (manufactures, sells, imports, and exports prescription drugs), Kyowa Kirin Co. (manufactures and sells prescription drugs), Torii Pharmaceutical Co. (manufactures and sells pharmaceuticals), Baxter (imports, manufactures, and sells dialysis products, plasma protein formulations, and drug administration systems), Sanofi KK (manufactures, sells, and imports pharmaceuticals and medical devices), and Takeda Pharmaceutical Co. (manufactures, sells, imports, and exports pharmaceuticals and quasi-drugs).

Hiroyuki Terawaki

Receives research funding from Sanwa Kagaku Kenkyusho Co. (researches, develops, manufactures, and sells pharmaceuticals, diagnostic agents, and other products)

Hidetomo Nakamoto

Receives research funding, lecture fees, writing fees, and other remuneration from Toray Industries Inc. (manufactures and sells pharmaceuticals and medical products), Kissei Pharmaceutical Co. (researches, develops, manufactures, and sells pharmaceuticals), Boehringer Ingelheim International GmbH (manufactures, sells, and imports pharmaceuticals), Terumo Corp. (manufactures and sells medical devices and pharmaceuticals), Astellas Pharma Inc. (manufactures, sells, imports, and exports pharmaceuticals), JCR Pharmaceuticals Co. (manufactures and sells raw materials for pharmaceuticals; imports and exports medical devices), Kyowa Kirin Co. (manufactures and sells prescription drugs), and Chugai Pharmaceutical Co. (manufactures and sells prescription drugs).

Mizuya Fukasawa

Receives research funding from Nipro Corp. (manufactures and sells medical devices and pharmaceuticals), Baxter (imports, manufactures, and sells dialysis products, plasma protein formulations, and drug administration systems), Nikkiso Co. (manufactures and sells dialysis products including hemodialysis equipment, dialyzers, dialysis blood circuit sets, kidney machine formulations, and artificial pancreases), and Terumo Corp. (manufactures and sells medical equipment and pharmaceuticals).

Akihiro C. Yamashita

Receives research funding, travel expenses for academic conferences and other events, and consultant fees from Nikkiso Co. (manufactures and sells dialysis products including hemodialysis equipment, dialyzers, dialysis blood circuit sets, kidney machine formulations, and artificial pancreases), Asahi Kasei Medical Co. (manufactures and sells medical devices), and Nipro Corp. (manufactures and sells medical devices and pharmaceuticals).

Hideki Yokoi

Receives research funding from Daiichi Sankyo Co. (researches, develops, manufactures, and sells prescription drugs), Baxter (imports, manufactures, and sells dialysis products, plasma protein formulations, and drug administration systems), and Mitsubishi Tanabe Pharma Corp. (manufactures and sells mostly prescription drugs).

Masaaki Nakayama

Receives research funding, lecture fees, writing fees, consultant fees, and other remuneration from Torii Pharmaceutical Co. (manufactures and sells pharmaceuticals), Pureron Japan Co. (designs, manufactures, and sells precision instruments and electronic devices), Alpha Electron Co. (develops and manufactures medical devices), Japan Tobacco Inc. (manufactures and sells tobacco, pharmaceuticals, food, and beverages), Nikkiso Co. (manufactures and sells dialysis products including hemodialysis equipment, dialyzers, dialysis blood circuit sets, kidney machine formulations, and artificial pancreases), Torii Pharmaceutical Co. (manufactures and sells pharmaceuticals), Baxter (imports, manufactures, and sells dialysis products, plasma protein formulations, and drug administration systems), Chugai Pharmaceutical Co. (manufactures, sells, imports, and exports prescription drugs), and Nihon Trim Co. (develops and sells medical water purifiers). Hidetoshi Kanai

Receives research funding and lecture fees from Baxter (imports, manufactures, and sells dialysis products, plasma protein formulations, and drug administration systems), Kyowa Kirin Co. (manufactures and sells prescription drugs), Mitsubishi Tanabe Pharma Corp. (manufactures and sells mostly prescription drugs), GlaxoSmithKline KK (researches, develops, imports, and manufactures prescription drugs, OTC drugs, and other products), Japan Tobacco Inc. (manufactures and sells tobacco, pharmaceuticals, food, and beverages), Bayer Yakuhin Ltd. (develops, imports, manufactures, and sells pharmaceuticals, medical equipment, and veterinary drugs), Terumo Corp. (manufactures and sells medical equipment and 
pharmaceuticals), and Kirin Holdings Co. (formulates business strategies and manages businesses).

Masahito Tamura

Receives research funding, lecture fees, and other remuneration from Baxter (imports, manufactures, and sells dialysis products, plasma protein formulations, and drug administration systems) and Otsuka Pharmaceutical Co. (manufactures, sells, exports, and imports pharmaceuticals, clinical tests, medical devices, and foods).

Hiroyasu Yamamoto

Receives lecture fees and other remuneration from Kyowa Kirin Co. (manufactures and sells prescription drugs) and Chugai Pharmaceutical Co. (manufactures, sells, imports, and exports prescription drugs). Hiroaki lo

Receives research funding or belongs to a department endowed by Takeda Pharmaceutical Co. (manufactures, sells, imports, and exports pharmaceuticals and quasi-drugs), Eisai Co. (manufactures and sells pharmaceuticals and quasi-drugs), Ono Pharmaceutical Co. (researches, develops, manufactures, purchases, and sells various pharmaceuticals, mainly prescription drugs), Sumitomo Dainippon Pharma Co. (manufactures and sells prescription drugs, diagnostic agents, and other products), Otsuka Pharmaceutical Co. (manufactures, sells, exports, and imports pharmaceuticals, clinical tests, medical devices, and foods), Asahi Kasei Pharma Corp. (manufactures and sells prescription drugs, diagnostic enzymes, diagnostic agents, and liquid foods), Mochida Pharmaceutical Co. (researches, develops, manufactures, and sells pharmaceuticals), Daiichi Sankyo Co. (researches, develops, manufactures, and sells prescription drugs), Shionogi \& Co. (manufactures and sells pharmaceuticals, diagnostic agents, and other products), Sanwa Kagaku Kenkyusho Co. (researches, develops, manufactures, and sells pharmaceuticals, diagnostic agents, and other products), Kyowa Kirin Co. (manufactures and sells prescription drugs), Kowa Pharmaceutical Co. (sells pharmaceuticals, medical devices, and medical consumables), Mitsubishi Tanabe Pharma Corp. (manufactures and sells pharmaceuticals, mainly prescription drugs), Novartis (develops, imports, manufactures, and sells pharmaceuticals), ZERIA Pharmaceutical Co. (manufactures and sells prescription and OTC drugs), Boehringer Ingelheim International GmbH (researches, develops, imports, manufactures, and sells pharmaceuticals), Torii Pharmaceutical Co. (manufactures and sells pharmaceuticals), Astellas Pharma Inc. (manufactures, sells, imports, and exports pharmaceuticals), Pfizer Inc. (develops pharmaceuticals), Chugai Pharmaceutical Co. (manufactures, sells, imports, and exports prescription drugs), Merck Sharp \& Dohme Corp. (develops, imports, manufactures, and sells pharmaceuticals, vaccines, and medical devices), and Sunstar Inc. (manufactures and sells toothpaste, toothbrushes, dental rinse, and other products).

Yoko Obata

Receives research funding from Otsuka Pharmaceutical Co. (manufactures, sells, imports, and exports pharmaceuticals, clinical examinations, medical equipment, and food products), Kyowa Kirin Co. (manufactures and sells prescription drugs), Daiichi Sankyo Co. (researches, develops, manufactures, and sells prescription drugs), Chugai Pharmaceutical Co. (manufactures and sells prescription drugs), Baxter (imports, manufactures, and sells dialysis products, plasma protein formulations, and drug administration systems), and Kaneka Medix Corp. (manufactures and sells medical devices).

Tsutomu Sakurada

Receives research funding from AstraZeneca KK (develops, manufactures, and sells prescription drugs), Shionogi \& Co. (manufactures and sells pharmaceuticals, diagnostic agents, and other products), Baxter (imports, manufactures, and sells dialysis products, plasma protein formulations, and drug administration systems), Astellas Pharma Inc. (manufactures, sells, imports, and exports pharmaceuticals), Kyowa Kirin Co. (manufactures and sells prescription drugs), Takeda Pharmaceutical Co. (manufactures, sells, imports, and exports pharmaceuticals and quasi-drugs), Teijin Pharma Ltd. (researches, develops, and manufactures pharmaceuticals and medical devices), and Ono Pharmaceutical Co. (researches, develops, manufactures, purchases, and sells pharmaceuticals, mainly prescription drugs). Hiraku Tsujimoto

Belongs to a department that receives research funding from Otsuka Pharmaceutical Co. (manufactures, sells, imports, and exports pharmaceuticals, clinical examinations, medical equipment, and food products), Astellas Pharma Inc. (manufactures, sells, imports, and exports pharmaceuticals), Takeda Pharmaceutical Co. (manufactures, sells, imports, and exports pharmaceuticals and quasi-drugs), iPS Portal Inc. (involved in the commercialization of iPS technology), and Nikkiso Co. (manufactures and sells dialysis products including hemodialysis equipment, dialyzers, dialysis blood circuit sets, kidney machine formulations, and artificial pancreases). Yasushi Tsujimoto

Belongs to a department that receives research funding from Kyowa Kirin Co. (manufactures and sells prescription drugs) and Data Horizon Corp. (involved in developing and providing medical-related data services). Naohiro Toda

Receives research funding from Baxter (imports, manufactures, and sells dialysis products, plasma protein formulations, and drug administration systems), Daiichi Sankyo Co. (researches, develops, manufactures, sells prescription drugs), and Mitsubishi Tanabe Pharma Corp. (manufactures and sells pharmaceuticals, mainly prescription drugs).

Yukio Maruyama

Receives research funding from Terumo Corp. (manufactures and sells medical devices and pharmaceuticals).

Kokichi Morimoto

Receives lecture fees and belongs to a department endowed by Baxter (imports, manufactures, and sells dialysis products, plasma protein formulations, and drug administration systems).

Naoki Washida

Belongs to a department endowed by Baxter (imports, manufactures, and sells dialysis products, plasma protein formulations, and drug administration systems).

Kimio Watanabe

Receives consultant fees from Nippon Trim Co. (develops and sells medical water purifiers).

Tsutomu Furuzono

Receives research funding and is a technical advisor to SofSera Corp. (develops and helps develop medical equipment and devices).

Ikuto Masakane

Receives research funding, lecture fees, and other remuneration from Chugai Pharmaceutical Co. (manufactures and sells prescription drugs), Torii

Pharmaceutical Co. (manufactures and sells pharmaceuticals), Kyowa Kirin Co. (manufactures and sells prescription drugs), Toray Medical Co. (manufactures, sells, imports, and exports medical devices, medical-related products, and pharmaceuticals), and Nipro Corp. (manufactures and sells medical devices and pharmaceuticals).

(in no particular order)

Members not listed here have no COI to declare.

cOl documents were checked for everyone except the outside evaluation committee members. Chairman Ito did not participate in the discussions of the SR or panel due to the COI involving the endowed department. Deputy Chairman Ryuzaki served in his place.

\section{Author details}

${ }^{1}$ Department of Nephrology, Tokyo Saiseikai Central Hospital, Tokyo, Japan. ${ }^{2}$ Department of Nephrology and Rheumatology, Aichi Medical University, Nagakute, Japan. ${ }^{3}$ Department of General Internal Medicine, Saitama Medical University, Saitama, Japan. ${ }^{4}$ College of Life Science, Ibaraki Christian University, Hitachi, Japan. ${ }^{5}$ Itami Kidney Clinic, Noboribetsu, Japan. ${ }^{6}$ Department of Nephrology and Dialysis Center, Yabuki Hospital, Yamagata, Japan. ${ }^{7}$ Department of Nephrology, Hitachi General Hospital, Hitachi, Japan. ${ }^{8}$ Department of Human Nutrition, Tokyo Kasei Gakuin University, Tokyo, Japan. ${ }^{9}$ Tsuchiya General Hospital, Hiroshima, Japan. ${ }^{10}$ Department of Nephrology, Tokyo Medical University, Tokyo, Japan. ${ }^{11}$ Department of Human Resource Development of Dialysis Therapy for Kidney Disease, Okayama University Graduate School of Medicine, Dentistry and Pharmaceutical Sciences, Okayama, Japan. ${ }^{12}$ Department of Nephrology, Nara Medical University, Kashihara, Japan. ${ }^{13}$ Department of Internal Medicine, Nephrology, Teikyo University Chiba Medical Center, Ichihara, Japan. ${ }^{14}$ Clinical Engineering Research Center Faculty of Medicine, Oita University, Oita, Japan.

${ }^{15}$ Department of Urology/Blood Purification Unit, Yamanashi University, Yamanashi, Japan. ${ }^{16}$ Department of Chemical Science and Technology, Faculty of Bioscience and Applied Chemistry, Hosei University, Tokyo, Japan.

${ }^{17}$ Department of Nephrology, Graduate School of Medicine, Kyoto University, Kyoto, Japan. ${ }^{18}$ Department of Nephrology, St. Luke's International Hospital, Tokyo, Japan. ${ }^{19}$ Department of Oral and Maxillofacial Surgery, National Hospital Organization Toyohashi Medical Center, Toyohashi, Japan.

${ }^{20}$ Department of Healthcare Epidemiology, School of Public Health, Graduate School of Medicine, Kyoto University, Kyoto, Japan. ${ }^{21}$ Department of Cell 
Growth and Differentiation, Center for iPS Cell Research and Application, Kyoto University, Kyoto, Japan. ${ }^{22}$ Department of Nephrology, Kasugai Municipal Hospital, Kasugai, Japan. ${ }^{23}$ Department of Nephrology, National Hospital Organization, Fukuokahigashi Medical Center, Koga, Japan.

${ }^{24}$ Department of Nephrology, Masuko Memorial Hospital, Nagoya, Japan.

${ }^{25}$ Department of Nephrology, Seirei Sakura Citizen Hospital, Sakura, Japan.

${ }^{26}$ Division of Community Medicine, Faculty of Medicine, Tohoku Medical and Pharmaceutical University, Sendai, Japan. ${ }^{27}$ Division of Blood Purification, Tohoku University Hospital, Sendai, Japan. ${ }^{28}$ Department of Nephrology, Nagasaki University Hospital, Nagasaki, Japan. ${ }^{29}$ Department of Nephrology, Nagoya City University Graduate School of Medical Sciences, Nagoya, Japan ${ }^{30}$ Department of Nephrology, Kansai Electric Power Hospital, Osaka, Japan.

${ }^{31}$ Department of Nephrology, Wakayama Medical University, Wakayama, Japan. ${ }^{32}$ Department of Internal Medicine, Inoue Hospital, Suita, Japan.

${ }^{33}$ Division of Nephrology and Hypertension, Department of Internal Medicine, St. Marianna University School of Medicine, Kawasaki, Japan.

${ }^{34}$ Department of Nephrology, Kawasaki Saiwai Hospital, Kawasaki, Japan.

${ }^{35}$ Division of Endocrinology, Metabolism and Nephrology Department of Internal Medicine, Keio University School of Medicine, Tokyo, Japan.

${ }^{36}$ Department of Nephrology, School of Medicine, International University of Health and Welfare, Narita, Japan. ${ }^{37}$ Apheresis and Dialysis Center, Keio University School of Medicine, Tokyo, Japan. ${ }^{38}$ Division of Nephrology and Hypertension, Department of Internal Medicine, The Jikei University School of Medicine, Tokyo, Japan. ${ }^{39}$ Department of Medicine, Shibagaki Dialysis Clinic, Tokyo, Japan. ${ }^{40}$ Department of Nephrology, Juntendo University Nerima Hospital, Tokyo, Japan. ${ }^{41}$ Department of Nephrology, Juntendo University Shizuoka Hospital, Shizuoka, Japan.

Received: 21 June 2020 Accepted: 22 January 2021

Published online: 06 September 2021

\section{References}

1. Nitta K, Masakane I, Tomo T, Tsuchida K, Ikeda K, Ogawa T, et al. Clinical Practice Guidelines (CPG) Creation Policy for the Japanese Society of Dialysis Therapy. J J.jn Soc Dial Ther. (in Japanese). 2016;49(7):453-62. https://doi.org/10.4009//sdt.49.453.

2. Aihara M. The GRADE System for Clinical Practice Guidelines, Second Edition. Hirosaki: Letterpress Media; 2015.

3. National Research Council. Clinical Practice Guidelines We Can Trust. Washington, DC: The National Academies Press; 2011.

4. The GRADE working group. GRADE. http://www.gradeworkinggroup.org/. Accessed 24 Apr 2017.

5. Higgins JPT, Green S. Cochrane Handbook for Systematic Reviews of Interventions Version 5.1.0. Hirosaki: The Cochrane Collaboration; 2011

6. Fukui T, Yamaguchi N. Minds process for creation of clinical practice guidelines. (in Japanese) Igaku Shoin. 2014. https://minds.jcghc.or.jp/s/doc_tool_manual.

7. Kojimahara N, Nakayama T, Morishima T, Yamaguchi MN, Yoshida M, et al. Minds Clinical Practice Guidelines Creation Manual 2017. Japan Council for Quality Health Care, EBM Medical Information Division. 2017. https://minds. jcahc.or.jp/s/doc_tool_manual.

8. Li PK, Chow K, Wong TY, Leung C, Szeto CC. Effects of an angiotensinconverting enzyme inhibitor on residual renal function in patients receiving peritoneal dialysis. A randomized, controlled study. Ann Intern Med. 2003; 139:105-12.

9. Wolfson M, Piraino B, Hamburger RJ, Morton AR; Icodextrin Study Group. A randomized controlled trial to evaluate the efficacy and safety of icodextrin in peritoneal dialysis. Am J Kidney Dis. 2002;40:1055-65.

10. Finkelstein F, Healy H, Abu-Alfa A, Ahmad S, Brown F, Gehr T, et al. Superiority of icodextrin compared with $4.25 \%$ dextrose for peritoneal ultrafiltration. J Am Soc Nephrol. 2005;16:546-54.

11. Lin A, Qian J, Li X, Yu X, Liu W, Sun Y, et al. Randomized controlled trial of icodextrin versus glucose containing peritoneal dialysis solution. Clin J Am Soc Nephrol. 2009;:1799-804.

12. Chang Tl, Ryu DR, Yoo TH, Kim HJ, Kang EW, Kim H, et al. Effect of icodextrin solution on the preservation of residual renal function in peritoneal dialysis patients: a randomized controlled study. Medicine. 2016; 95:1-10.

13. Nanamatsu A, Katsuragawa F, Kawai S, Yanagi T, Higuchi S, Yajima Y, et al. A case of a peritoneal dialysis patient suspected of liver and renal injury due to icodextrin dialysis solution. J Jpn Soc Dial Ther (in Japanese). 2017;50: 309-13.
14. Nitta K, Masakane I, Hanafusa N, Taniguchi M, Hasegawa T, Nakai S, et al. The current state of chronic dialysis therapy in Japan (As of 12/31/ 2017). J Jpn Soc Dial Ther (in Japanese). 2018;51:699-766. https://doi.org/10.4009/ jsdt.51.699.

15. Chu KH, Choy WY, Cheung CC, Fung KS, Tang HL, Lee W, et al. A prospective study of the efficacy of local application of gentamicin versus mupirocin in the prevention of peritoneal dialysis catheter-related infections. Perit Dial Int. 2008;28:505-8.

16. Wright MJ, Bel'eed K, Johnson BF, Eadington DW, Sellars L, Farr MJ. Randomized prospective comparison of laparoscopic and open peritoneal dialysis catheter insertion. Perit Dial Int. 1999;19:372-5

17. Bennett-Jones D, Penny WW, Taube MD, Chisholm GN, Cameron OJS, Williams DG. A comparison of intraperitoneal and intravenous/oral antibiotics in CAPD peritonitis. Pert Dial Int. 1987;7:31-3. https://doi.org/10.11 77/089686088700700109

18. Bailie GR, Morton R, Ganguli L, Keaney M, Waldek S. Intravenous or intraperitoneal vancomycin for the treatment of continuous ambulatory peritoneal dialysisassociated gram-positive perinonitis? Nephron. 1987;46: 316-8. https://doi.org/10.1159/000184374.

19. Korevaar JC, Feith GW, Dekker FW, van Manen JG, Boeschoten EW, Bossuyt PM, et al. Effect of starting with hemodialysis compared with peritoneal dialysis in patients new on dialysis treatment: a randomized controlled trial. Kidney Int. 2003;64:2222-8. https://doi.org/10.1046/j.1523-1755.2003.00321.x.

\section{Publisher's Note}

Springer Nature remains neutral with regard to jurisdictional claims in published maps and institutional affiliations.

\section{Ready to submit your research? Choose BMC and benefit from:}

- fast, convenient online submission

- thorough peer review by experienced researchers in your field

- rapid publication on acceptance

- support for research data, including large and complex data types

- gold Open Access which fosters wider collaboration and increased citations

- maximum visibility for your research: over $100 \mathrm{M}$ website views per year

At BMC, research is always in progress.

Learn more biomedcentral.com/submissions 